\title{
Smoke Plume Trajectory from In Situ Burning of Crude Oil in Alaska: Field Experiments
}

Kevin B. McGrattan

William D. Walton

Anthony D. Putorti

William H. Twilley

Jay McElroy

David D. Evans

November 1995

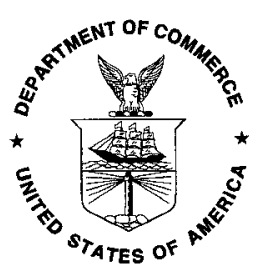

U.S. Department of Commerce

Ronald H. Brown, Secretary

National Institute of Standards and Technology

Arati Prabhakar, Director
Prepared for the

Alaska Department of Environmental Conservation

Division of Spill Prevention and Response 


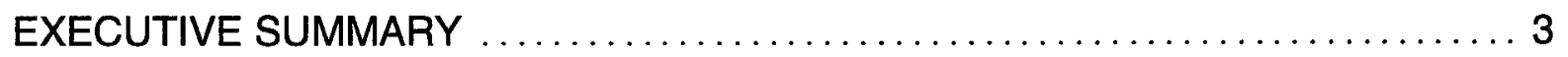

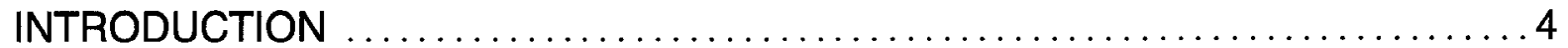

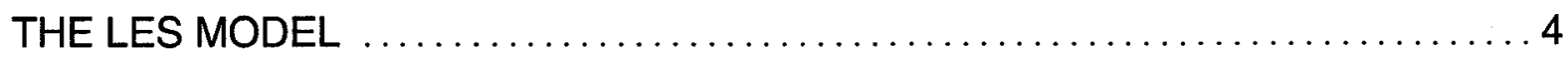

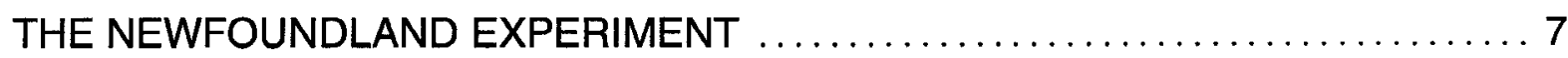

ALASKA CLEAN SEAS EMULSION BURN TEST ...................... 13

DISCUSSION ............................................ 22

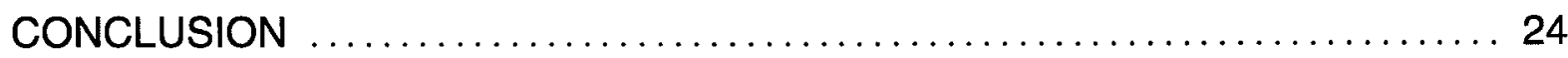

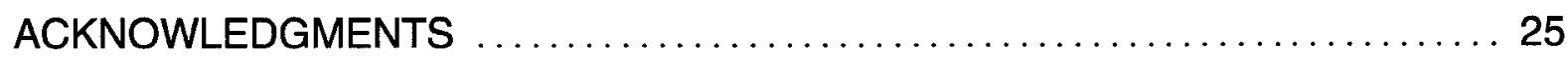

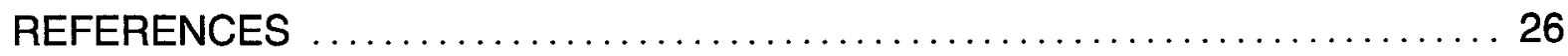

APPENDIX: ACS EMULSION BURN RAM DATA $\ldots \ldots \ldots \ldots \ldots \ldots \ldots \ldots \ldots \ldots$ 


\section{LIST OF FIGURES}

Figure 1. Downwind view of a computed smoke plume $\ldots \ldots \ldots \ldots \ldots \ldots \ldots$

Figure 2. Photograph of plume showing two counter-rotating vortices $\ldots \ldots \ldots \ldots 8$

Figure 3. Atmospheric conditions for second NOBE burn $\ldots \ldots \ldots \ldots \ldots \ldots$

Figure 4. Cross sectional slices of simulated plume of second NOBE burn ....... 10

Figure 5. Cross sectional slices of second NOBE plume from LIDAR ......... 11

Figure 6. LIDAR measurement of plume centerline $\ldots \ldots \ldots \ldots \ldots \ldots \ldots \ldots \ldots \ldots$

Figure 7. Aerial view of second ACS burn ............................. 14

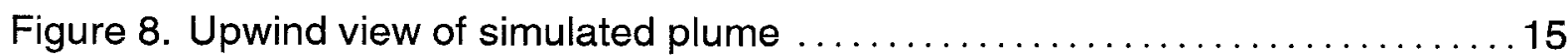

Figure 9. Summary of numerical simulation of the first ACS burn ........... 18

Figure 10. Summary of numerical simulation of the second ACS burn ......... 19

Figure 11. Summary of numerical simulation of the third ACS burn ...........20

Figure 12. Summary of ground level particulate concentration for all ACS burns .. 21

Figure 13. Location of the RAMS for the three ACS burns $\ldots \ldots \ldots \ldots \ldots \ldots . \ldots 28$

Figures 14-24. RAM data for ACS burns . . . . . . . . . . . . . . . . . . . . 29-39

\section{LIST OF TABLES}

Table 1. Summary of the ACS Emulsion Burns 


\title{
SMOKE PLUME TRAJECTORY FROM IN SITU BURNING OF CRUDE OIL IN ALASKA - FIELD EXPERIMENTS
}

\author{
Kevin B. McGrattan, William D. Walton, Anthony D. Putorti, \\ William H. Twilley, Jay McElroy and David D. Evans \\ National Institute of Standards and Technology \\ Gaithersburg, Maryland 20899
}

\section{EXECUTIVE SUMMARY}

As part of their effort to assess the impact of smoke plumes from in situ burning of crude oil on nearby populations [1], the Alaska Regional Response Team and the Alaska Department of Environmental Conservation established a Cooperative Research and Development Agreement with the National Institute of Standards and Technology (NIST) in 1993 with the intent of developing predictive methods to estimate the downwind concentration of particulate matter from a burning oil spill. The first phase of the study consisted of laboratory-scale burns of North Slope and Cook Inlet crude oils, the results of which were used to define the source terms for the LES (Large Eddy Simulation) plume trajectory model. A number of different fire sizes and weather conditions were considered with the aim of estimating the extent to which concentrations of smoke particulate matter would exceed ambient air quality standards. Recommendations were made in a previously published report [2].

In the present report, experimental data collected at two sets of mesoscale burns are compared with the results of the LES model run using the recorded meteorological and physical conditions. The two experiments are the Newfoundland Offshore Burn Experiment (NOBE), Aug. 1993, and the Alaska Clean Seas Burning of Emulsions, Sept. 1994. Each series of burns was conducted under different conditions, and different data collection techniques were employed at each. The results show that the predictions of the LES model are in good agreement with the experimental measurements, given the uncertainty of the input parameters. This increases confidence in the accuracy of the predicted results reported in the original study, and it also provides guidance on how to assess the uncertainty of model predictions. The original report was written without the benefit of field data to validate the physical assumptions of the model; thus it was suggested that a factor of safety of 2 be applied to a model prediction to account for both the uncertainties in the input parameters and the physical assumptions of the model. The results of the field experiments, however, suggest that the uncertainty of the model prediction is commensurate with the uncertainty of the input parameters. This is not to say that the model is perfect, but rather that the uncertainties due to the physical assumptions of the model are outweighed by the uncertainties due to the input parameters. 


\section{INTRODUCTION}

The Alaska Regional Response Team (ARRT) has been working over the past two or three years to develop procedures and guidelines to facilitate the decision process regarding in situ burning of crude oil. As part of their effort to assess the impact of smoke plumes from in situ burning on nearby populations, the ARRT and the Alaska Department of Environmental Conservation (ADEC) established a Cooperative Research and Development Agreement (CRADA) with the National Institute of Standards and Technology (NIST) in 1993. Phase I of this project was completed in 1993, and the results have been documented in a report which has been delivered to ADEC [2]. Briefly, laboratory-scale experiments were conducted to determine the heat release rate and smoke yield from two types of Alaskan crude oils, North Slope and Cook Inlet. These experiments were used to determine the input parameters for the Large Eddy Simulation (LES) model of smoke transport, version 2.0, which predicts the concentration of combustion products downwind of a large fire. In processing the results of the model, special attention was given to the downwind and lateral extent of ground level ${ }^{1}$ particulate concentrations in excess of $150 \mu \mathrm{g} / \mathrm{m}^{3}$ averaged over one hour. Although there is no formal guidance available concerning safe levels of short term exposure to particulate emissions from oil fires, $150 \mu \mathrm{g} / \mathrm{m}^{3}$ averaged over 24 hours is the upper level established under air quality control regulations in Alaska $^{2}$. For meteorological conditions typical of the northern and southern coasts of Alaska, the calculations showed that hour-averaged particulate concentrations found at the ground downwind of oil spill burns would not exceed $150 \mu \mathrm{g} / \mathrm{m}^{3}$ beyond $5 \mathrm{~km}$, nor outside of a strip approximately $1 \mathrm{~km}$ wide along the centerline of the plume trajectory. It was suggested, however, that a factor of safety of 2 be applied to these results due to the lack of field verification at that time for the assumptions inherent in the model.

The intent of the present work is to analyze the results from two recent mesoscale burn experiments, and to compare these results with those predicted by the LES model. The first series is the Newfoundland Offshore Burn Experiment (NOBE) conducted by Environment Canada in August 1993. The second is the Burning of Emulsions Test conducted by Alaska Clean Seas in September 1994. For each series of burns, the LES model was run for the recorded meteorological and burn conditions, and the results were compared with data collected in the field. The measurement techniques for the two series of experiments varied, thus each experiment will be described separately.

\section{THE LES MODEL OF SMOKE PLUME TRAJECTORY}

Following is a brief description of the LES model. Further details may be found in References [2], [3], and [4]. The model consists of the conservation equations of mass, momentum and energy which describe the steady-state, convective transport of heated gases introduced into the atmosphere by a steadily burning fire and blown by a uniform ambient wind. The fire itself is not modeled; the main interest is in the downrange smoke

'Throughout this report, "ground level" will refer to the first $10 \mathrm{~m}(30 \mathrm{ft})$ of the atmosphere.

${ }^{2}$ Title 18, Alaska Administrative Code, Chapter 50, Citation 20 (AAC 50.020) Ambient Air Quality Standards. 
plume. The fire is represented as a source of heat and smoke, but not necessarily a point source. Only the overall surface area of the fire, its heat release rate and smoke yield of the fuel are required from experiments. The local meteorological conditions which must be provided are the wind speed, the local fluctuation of the wind from the prevailing direction, and the temperature stratification of the atmosphere. This model differs from most of the atmospheric dispersion models in use today because it is a deterministic rather than an empirical model. The approach taken is to solve the equations governing the flow directly rather than relying on empirical formulae which approximate the extent of the dispersion. These empirical models typically assume the pollutant of interest to be Gaussian distributed in the plane perpendicular to the direction of the prevailing wind. The parameters defining the distribution are estimated from experiments. Unfortunately, the problem of in situ burning of crude oil is inappropriate for these types of models for two reasons: (1) The nature of the "source" is different from the smokestacks which are usually assumed by such models, and (2) the size of the source is well beyond those considered in industrial applications and thus outside of the experimental parameter range used to calibrate the models.

Figure 1 displays the results of a typical LES model calculation. The surface shown defines the outer extent of the plume, i.e. where the particulate concentration drops off to background. References [3] and [4] contain details about the scaling and numerical solution of the governing equations. The basic approach is to transform the three-dimensional, steady state set of conservation equations which govern the plume transport into a twodimensional, time-dependent system by replacing the downwind spatial coordinate with a pseudo-temporal coordinate. The result is an initial value problem in which the temperature and mass distributions of the smoke plume are initially prescribed in a plane perpendicular to the direction of the prevailing wind. This initial plane is taken to be a few fire diameters downwind of the fire. The total mass and energy fluxes are determined from the experimentally obtained smoke yield and convective heat release rate ${ }^{3}$. Based on experimental observations, the initial particulate distribution is best taken as uniform, and the temperature Gaussian. Previous studies, including Reference [2], took the initial particulate concentration to be Gaussian as well. This resulted in excessive ground level predictions within the first kilometer which were not seen in the experiments. However, the overall conclusions of the study are not changed since the predictions of the $150 \mu \mathrm{g} / \mathrm{m}^{3}$ limit distance was not affected by the choice of initial distribution.

Atmospheric turbulence effects mixing on a wide range of scales, extending to scales which are smaller than the resolution of the calculations performed here. The small scale mixing is represented in the governing equations by a constant eddy viscosity, which is taken to be three orders of magnitude greater than the actual viscosity of air. The choice is governed by the desire for resolution limits in the five to fifteen meter range which are needed to capture the large scale fire-induced eddy motions. This requirement, together with the knowledge that the dissipative effects operate at length scales which are of the order of the overall geometric scale divided by the square root of the Reynolds number, yields Reynolds numbers of order $10^{4}$. For this problem, the geometric scale is

${ }^{3}$ I $t$ is assumed that a fraction of the total heat release rate is lost to thermal radiation which does not contribute to the rise of the smoke plume. For very sooty fires like those considered here, this radiative fraction has been estimated to be about $10 \%$ [7] 


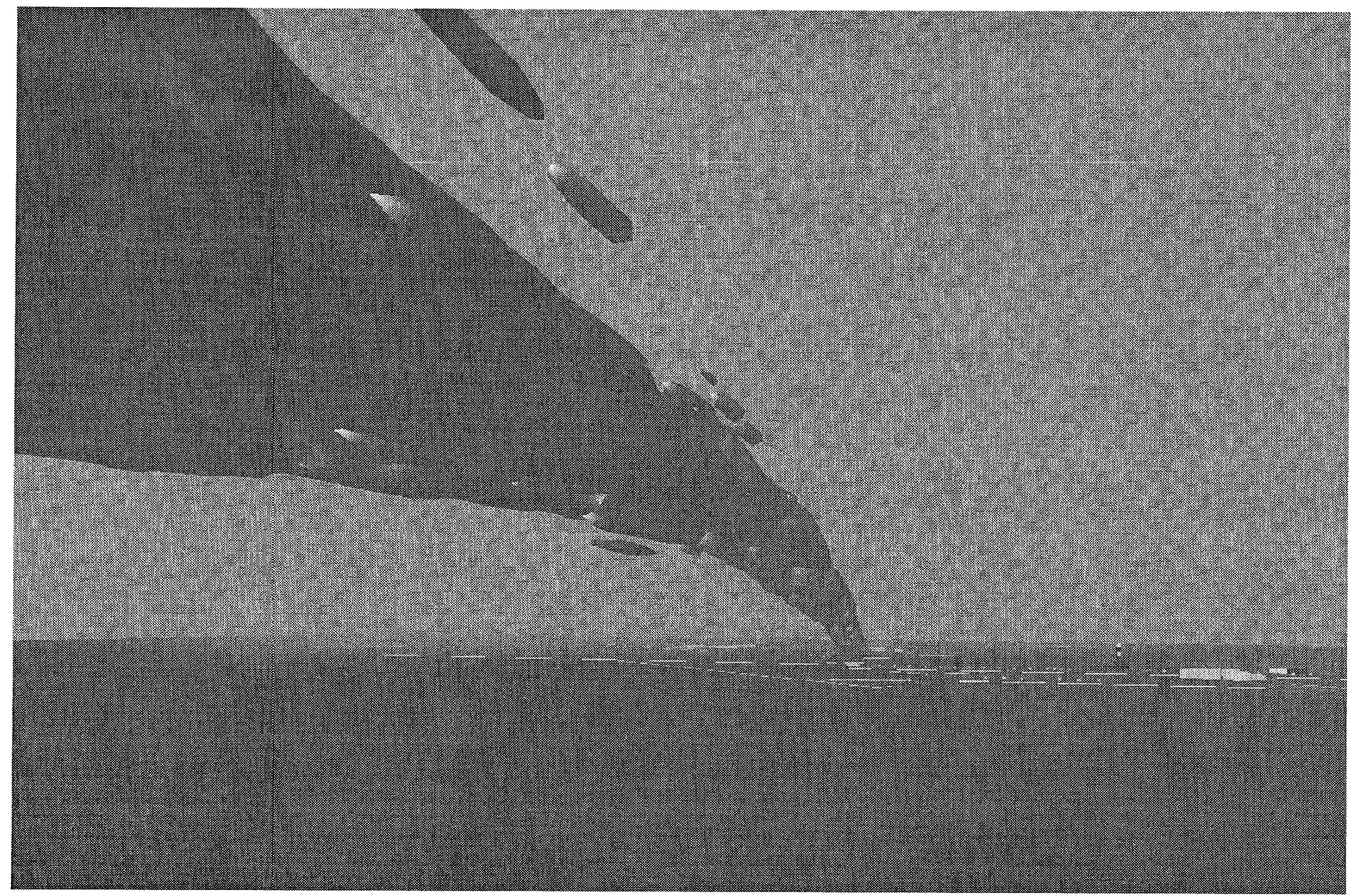

Figure 1: Downwind view of a computed smoke plume simulating one of the Alaska North Slope Emulsion Burns. 
the stabilization height of the plume. However, the magnitude of the diffusive terms in the governing equations do not account for large scale atmospheric motion, such as the random shifting of the wind direction over the length and time scales considered, which may be tens of kilometers and a few hours, respectively. These wind fluctuations can be measured, and are introduced into the model as random perturbations to the trajectories of the Lagrangian particles which represent the particulate matter. Details of this procedure may be found in Reference [2].

\section{THE NEWFOUNDLAND OFFSHORE BURN EXPERIMENT}

The Newfoundland Offshore Burn Experiment (NOBE) provided an enormous amount of data regarding in situ burning of oil at sea. The experiment consisted of two in situ burns of crude oil conducted off the coast of St. John's, Newfoundland on August 12, 1993. Results of the overall experiment may be found in Reference [5]. Most of the data collected concerns the composition of the emissions from the fire rather than their downwind dispersion. However, Dr. R.J. Ferek of the University of Washington's Cloud and Aerosol Research Group led a team of scientists in performing airborne measurements of the emission from the two in situ burns of crude oil. Of particular importance to the present study are the LIDAR measurements of the plume cross section, and the real-time monitoring of $\mathrm{CO}_{2}$ level in the plume.

An interesting photograph of the developing smoke plume is shown in Figure 2. As predicted by the calculations, the entrainment of air into the plume is dictated by two large counter-rotating vortices shown in the photograph. These structures are seen in the simulated smoke plume as well. The term "entrainment" is frequently used in fire research to describe the mixing of combustion products with fresh air. The extent to which the plume is diluted determines its ultimate rise and dispersion, thus it is crucial that this process be accounted for by the numerical model.

More data is available for the second burn, so that one will be used for the comparison. For this burn, it was reported that $28.9 \mathrm{~m}^{3}$ of crude oil of density $843.7 \mathrm{~kg} / \mathrm{m}^{3}$ was burned in 1.3 hours [5]. For the purposes of modeling the plume, it was assumed that the burning rate was constant at $5.2 \mathrm{~kg} / \mathrm{s}$. Based on previous work with Louisiana crude ${ }^{4}$ [4], the regression rate of the oil was estimated to be about $3.6 \mathrm{~mm} / \mathrm{min}$. Thus, the average area of the burning surface was about $100 \mathrm{~m}^{2}\left(950 \mathrm{ft}^{2}\right)$. Also based on previous work with Louisiana crude, the effective heat of combustion of the oil was assumed to be $42,000 \mathrm{~kJ} / \mathrm{kg}$. The smoke yield for the burn was measured by the team from NIST to be $15 \%$ [6], and the fraction of the total heat release lost as radiation was assumed to be $10 \%$ [7]. Thus, the convective heat release rate for the model run was about $200 \mathrm{MW}$ and the particulate production rate was $0.78 \mathrm{~kg} / \mathrm{s}$. Temperature soundings taken from the University of Washington aircraft [8] and from the NIST tethered blimp [6] indicate that the temperature profile of the first few hundred meters of the atmosphere showed an inversion (see Figure 3). The wind speed at the ground was $6 \mathrm{~m} / \mathrm{s}$, increasing to $8 \mathrm{~m} / \mathrm{s}$

${ }^{4}$ Even though Louisiana crude oil was not used in the experiment, the heats of combustion and burning rates do not vary dramatically from one type of crude oil to the next. In fact, both Alaska North Slope crude and Cook Inlet crude have burning properties similar to Louisiana crude. 


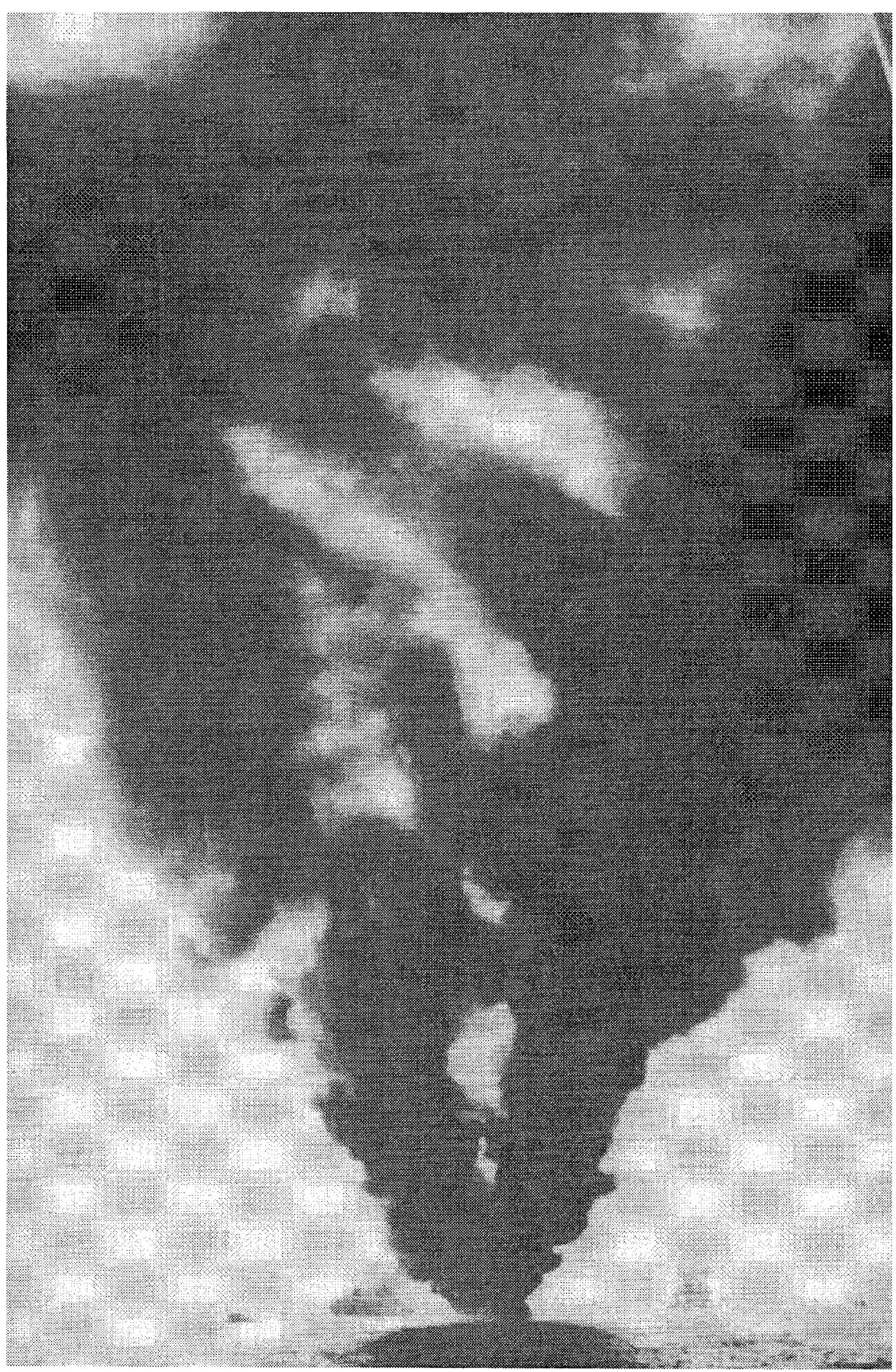

Figure 2: Photograph taken just downwind of second NOBE burn showing the development of two counter-rotating vortices. 

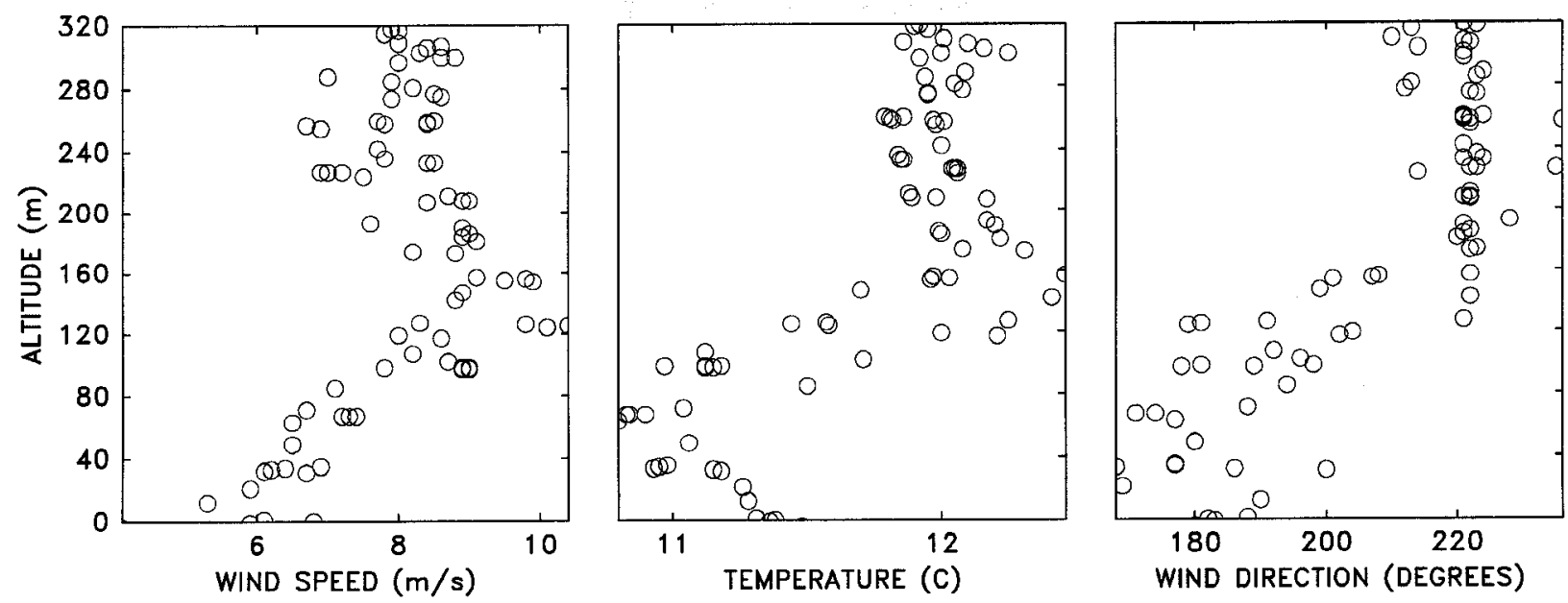

Figure 3: Atmospheric conditions for the second NOBE burn. The profile is based on measurements taken by the NIST tethered blimp. The measurements taken at higher altitudes by the University of Washington aircraft show no dramatic changes in any of the conditions beyond $300 \mathrm{~m}$.

a few hundred meters up. This was accompanied by a shift of roughly 30 to $40^{\circ}$ in the direction of the wind. To account for this dramatic wind shear, the current LES model (version 2.0) was modified to accommodate changes in wind direction with altitude (It is now referred to as version 2.1).

Figure 4 displays cross sections of the simulated plume at downwind locations which approximately match the locations of measurements taken by the University of Washington team (See Figure 5). The effect of the shift in the wind direction at about $120 \mathrm{~m}$ in altitude is obvious in both the simulated and the actual plume cross sections. There is reasonably good qualitative and quantitative ${ }^{5}$ agreement between the two for a distance of about 6 kilometers from the fire. Beyond this point the simulation breaks down due to a lofting of the actual plume to a height of about $700 \mathrm{~m}$. A LIDAR measurement (Figure 6) taken along the plume centerline shows the plume initially rising to a height of about $200 \mathrm{~m}$, leveling off for about $5 \mathrm{~km}$, and then gradually rising to a height of about $600 \mathrm{~m}$ after $20 \mathrm{~km}$. No measurable amount of particulate was detected near the surface. The model prediction showed small concentrations of particulate (below $50 \mu \mathrm{g} / \mathrm{m}^{3}$ ) near the surface, but away from the plume centerline. The centerline of the simulated plume reached a height of about $250 \mathrm{~m}$, but does not exhibit the gradual rise observed by the aircraft. It is unclear exactly why it occurs. It has been speculated that this lofting might be due to the heat generated by the absorption of sunlight by the dark plume [8]. This effect is not accounted for in the numerical model.

In addition to LIDAR measurements, the University of Washington aircraft made a number of other measurements. Of interest to this study are measurements of $\mathrm{CO}_{2}$. Measurements of $\mathrm{CO}_{2}$ are often made in conjunction with particulate measurements because practically all of the carbon in the fuel is converted by combustion to either $\mathrm{CO}_{2}$ or particu-

${ }^{5}$ This quantification is based on an analysis of the scattering characteristics of the individual smoke particles. Details of the analysis may be found in Reference [8]. 

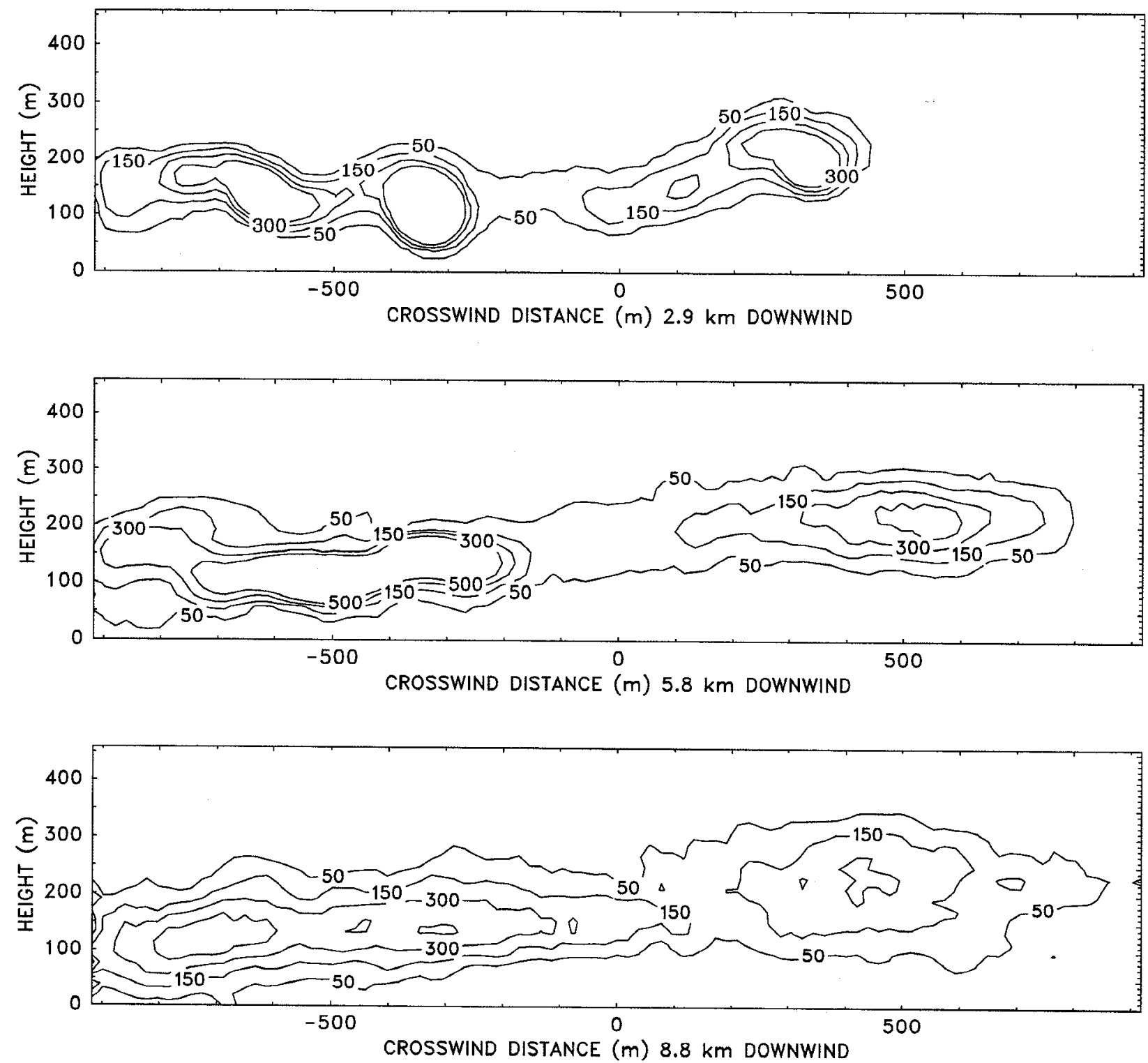

Figure 4: Cross sectional slices of the simulated smoke plume from the second NOBE burn using the LES model version 2.1. Shown are particulate concentration contours of 50,150 and $300 \mu \mathrm{g} / \mathrm{m}^{3}$ at three locations downwind corresponding to where LIDAR measurements were taken. The vertical length scale indicates height above sea level, while the horizontal scale indicates the distance from the assumed plume centerline. 


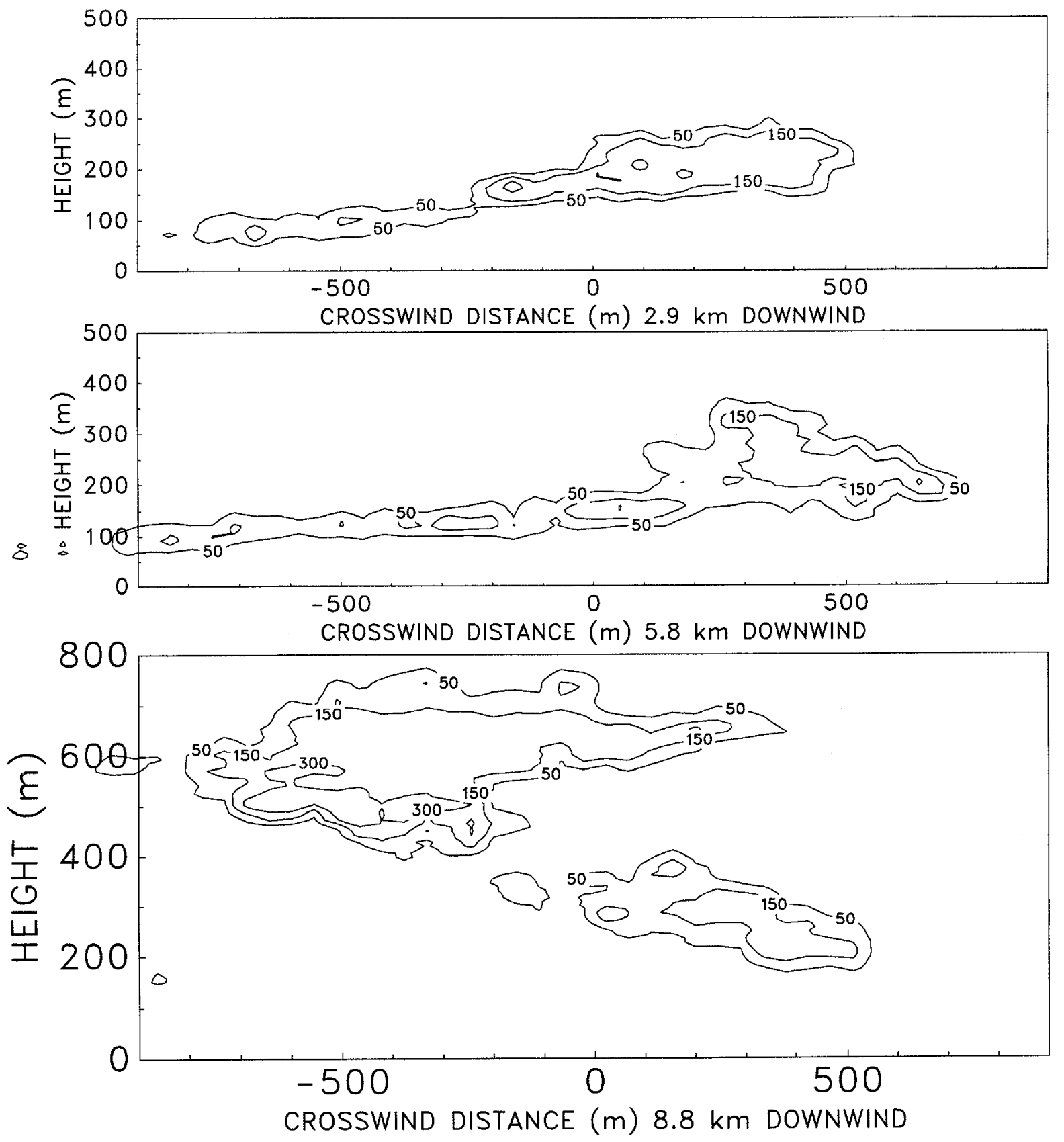

Figure 5: Cross sectional slices of the actual smoke plume from the second NOBE burn, courtesy of the University of Washington Cloud and Aerosol Research Group. Shown are contours of particulate concentration at 50,150 and $300 \mu \mathrm{g} / \mathrm{m}^{3}$. The crosswind scale indicates relative distances, and the origin was chosen to compare with the simulation. 


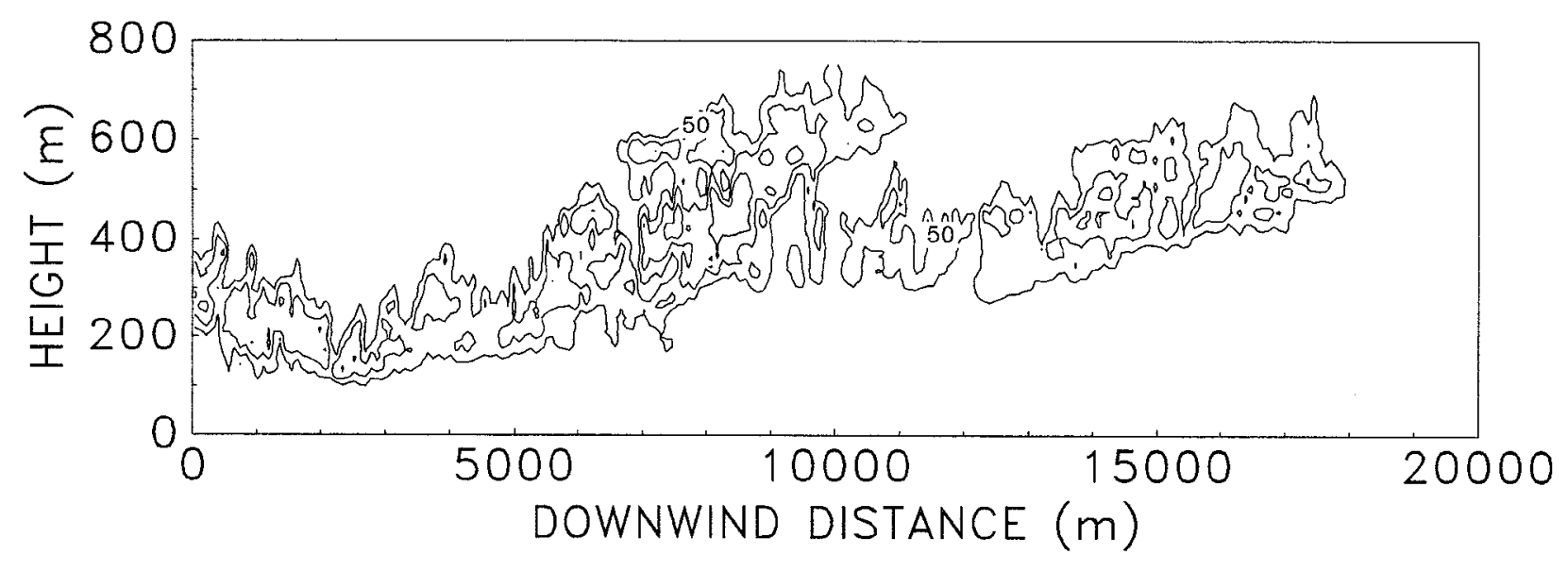

Figure 6: LIDAR measurement of plume centerline of the second burn taken from University of Washington aircraft. Note that the horizontal and vertical length scales are very different. In actuality, the plume shown is a long, slender object. Also, the origin of the plot is about $0.9 \mathrm{~km}$ from the actual fire.

late matter. The ratio of the two quantities in the smoke plume is relatively unchanging [9]. Because of this, plume particulate concentrations may be derived either by quantifying LIDAR cross section data as shown above, or by directly measuring the excess $\mathrm{CO}_{2}$ and deriving the particulate concentration based on the experimentally measured ratio of $\mathrm{CO}_{2}$ and particulate. Direct measurements of $\mathrm{CO}_{2}$ made while flying the aircraft along the centerline of the plume have been used to estimate the concentration of particulate matter. Taking the smoke yield to be $15 \%$ (from the NIST tethered blimp) and the elemental carbon mass fraction of the fuel to be 0.8664 ; it is estimated that $1 \mathrm{ppm}$ excess $\mathrm{CO}_{2}$ corresponds to a particulate concentration of $103 \mu \mathrm{g} / \mathrm{m}^{3}$. Direct measurements of excess $\mathrm{CO}_{2}$ by the University of Washington team found volume fractions decreasing to about $1.5 \mathrm{ppm}$ (the equivalent of $150 \mathrm{\mu g} / \mathrm{m}^{3}$ particulate) by about $16 \mathrm{~km}$ downwind of the burn. These measurements were taken at an altitude of about $500 \mathrm{~m}$. The quantified LIDAR images are consistent with this finding. The model calculation predicts that concentrations in excess of $150 \mu \mathrm{g} / \mathrm{m}^{3}$ extend slightly farther than $20 \mathrm{~km}$ downwind at altitudes of 200 to $300 \mathrm{~m}$.

The difference in the experimental measurements and the model prediction is due mainly to the enhanced plume dispersion caused by the unexpected lofting. Also, the comparison is being made based on only one pass of the aircraft along the plume centerline, which may not account for the maximum concentration. Indeed, the model predicts and visual sightings confirm the existence of counter-rotating vortices generated by the fire (see Figure 2) which entrain a substantial fraction of the particulate. The interaction of the vortices with the shear layer produced a very complicated cross-sectional profile, as seen in both the measured and computed cross-sections above. Thus, it is not necessarily true that the maximum concentration of particulate would be found along the centerline of the plume, even if it were possible to define a centerline. Indeed, the severe wind shear observed at the site spread the plume over a wide path. At $20 \mathrm{~km}$ from the burn site, the University of Washington aircraft recorded the lateral width of the plume to be about $5 \mathrm{~km}$. 


\begin{tabular}{|l|c|c|c|}
\hline \multicolumn{4}{|c|}{ Alaska Clean Seas Meso-Scale Emulsion Burns } \\
\hline \hline & Burn 1 & Burn 2 & Burn 3 \\
\hline \hline Date & Sept. 8 & Sept. 10 & Sept. 11 \\
\hline Volume of Emulsion $\left(\mathrm{m}^{3}\right)$ & 7.7 & 12.2 & 16.6 \\
\hline Percent Oil & $50 \%$ & $100 \%$ & $60 \%$ \\
\hline Oil Mass (kg) & 3768 & 10827 & 6545 \\
\hline Oil Removal Efficiency & $97.3 \%$ & $98.4 \%$ & $96.7 \%$ \\
\hline Burn Time (minutes) & 47 & 40 & 45 \\
\hline Estimated Heat Release Rate (MW) & 55 & 186 & 98 \\
\hline Estimated Particulate Mass Flux (kg/s) & 0.15 & 0.51 & 0.27 \\
\hline
\end{tabular}

\section{Table 1: Summary of the ACS Meso-Scale Emulsion Burns.}

\section{ALASKAN CLEAN SEAS EMULSION BURN TEST}

In early September 1994, Alaska Clean Seas conducted at the Fire Training Ground in Prudhoe Bay, Alaska, three meso-scale burns to determine the feasibility of burning emulsified oil [10]. Although the primary intent of the experiment was to test some emulsion breaking techniques, it provided a good opportunity to test the LES model of a smoke plume trajectory. An aerial view of one of the burns is shown in Figure 7.

At the request of the Alaska office of the US Environmental Protection Agency, the EPA's Emergency Response Team (EPA/ERT) came to Prudhoe Bay with 12 MIE Realtime Aerosol Monitors (RAM-1). These instruments employ a sensing principle that is based on the detection of near-forward electromagnetic radiation in the near infrared. The amount of scattered radiation detected quantifies particulate and aerosol concentrations ${ }^{6}$. Although the instruments cannot discriminate smoke particles from dust or other airborne particulate, the background readings taken prior to the burns were near zero, indicating a low level of other particulate. The twelve instruments were set out on tripods about 1 meter off the ground, spread out in rows of three or four, at distances ranging from 1 to 5 $\mathrm{km}$ from the burn site. The deployment strategy varied from burn to burn, depending on the weather conditions and the terrain over which the plume was expected to travel. The instruments were set to sample every second, and then log the 5 second average. Global positioning instruments recorded the locations of the individual devices. The instrument locations relative to the burn pit, along with the recorded particulate concentrations for each instrument, are included in the Appendix.

Table 1 summarizes the three meso-scale emulsion burns. Each consisted of burning an oil mixture within the confines of a fireproof circular boom which floated in a pit filled

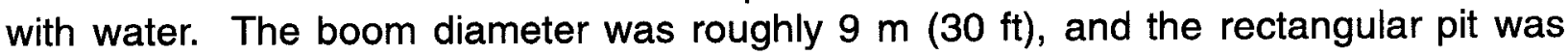
roughly $20 \mathrm{~m}$ by $30 \mathrm{~m}$. The burning area was about $64 \mathrm{~m}^{2}\left(700 \mathrm{ft}^{2}\right)$. The first and third

${ }^{6}$ The real-time aerosol monitors (RAMs) were equipped with an air intake separator to eliminate particulate larger than 10 microns in size. Thus, the particulate recorded can be categorized as PM-10. 


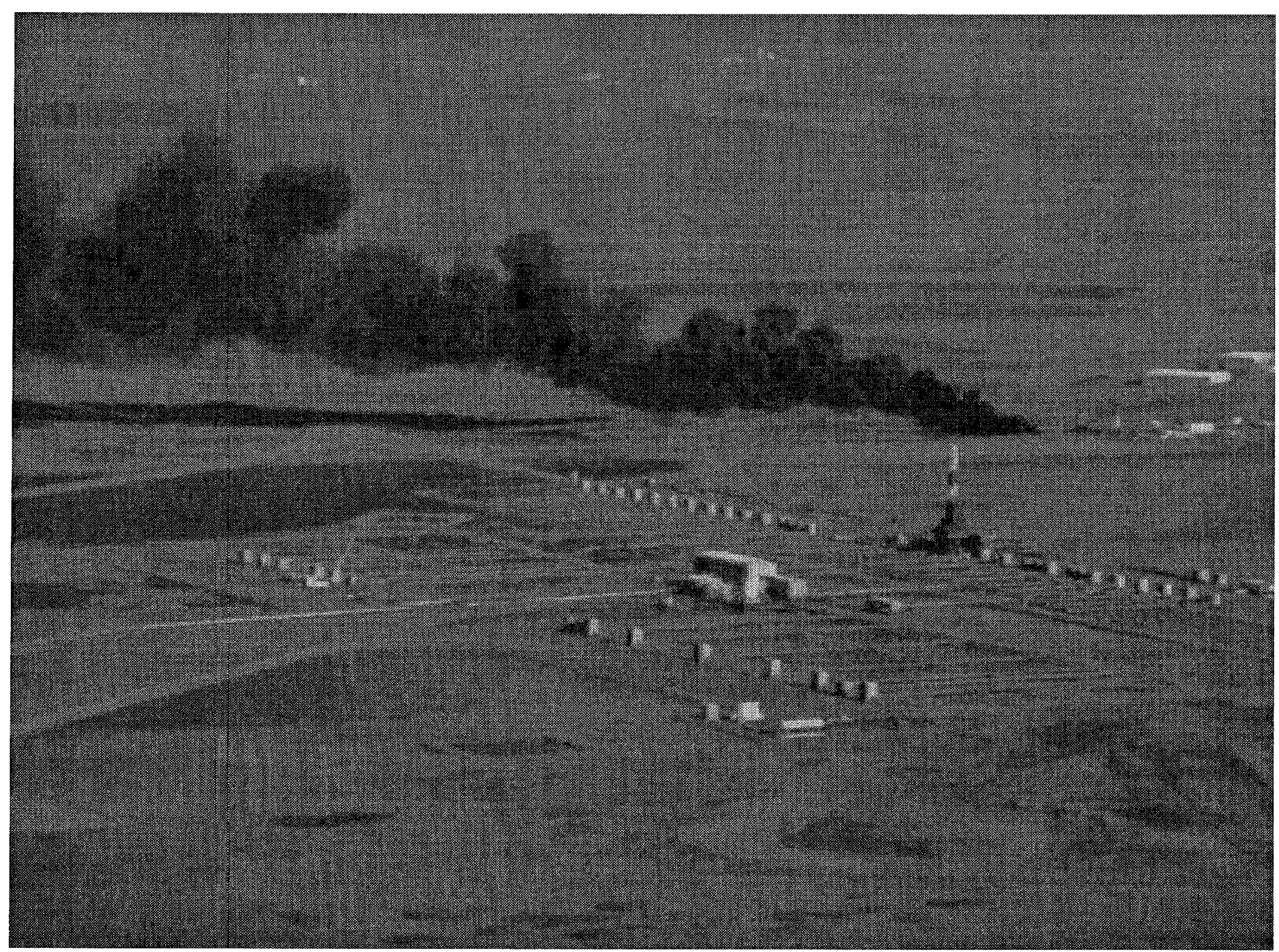

Figure 7: Aerial view of second ACS burn, Prudhoe Bay, Alaska, September 1994. 


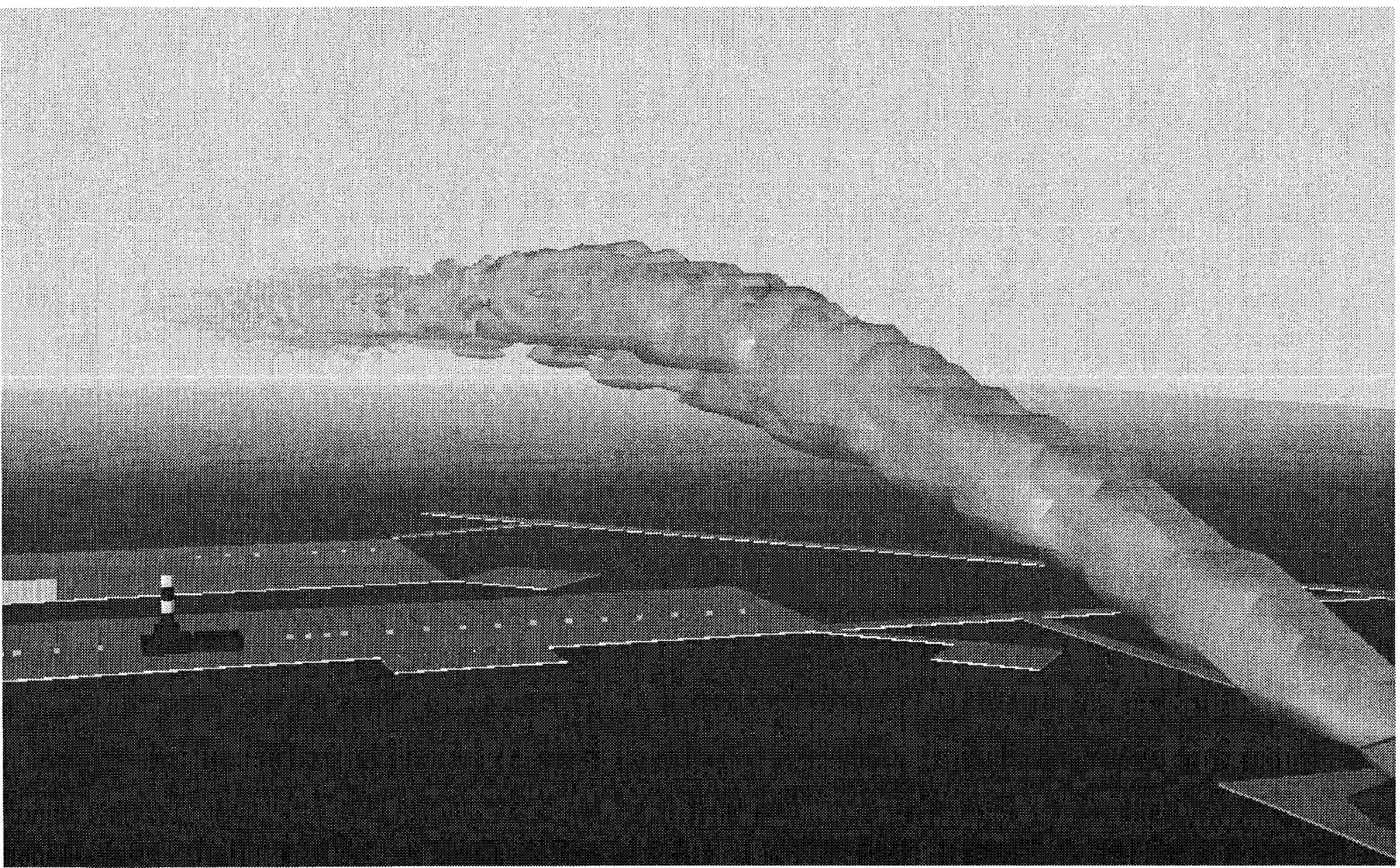

Figure 8: View of the simulated plume of the second ACS burn, as seen from upwind. The plume reaches a maximum height of about $400 \mathrm{~m}$. 
burns consumed emulsions of salt water and $17.4 \%$ evaporated ANS crude. The second burn consumed fresh ANS crude. To compute the average heat release rate for the burns, the mass of oil consumed (Oil Mass $\times$ Removal Efficiency) was multiplied by a heat of combustion of $42,000 \mathrm{~kJ} / \mathrm{kg}^{7}$ and then divided by the number of seconds needed to consume the oil. As an input to the LES model, an estimate is made that $90 \%$ of the total heat release rate may be considered the convective heat release rate, that is, $90 \%$ of the heat from the fire is lofted into the plume. The remaining $10 \%$ of the heat released is assumed to be radiated away, and plays no role in the model. The particulate mass flux was determined by multiplying the mass of oil consumed by the measured smoke yield of ANS crude (11.6\%), divided by the burn time. Burn times are estimated from visual estimates of the fire size based on the percentage of the boom area on fire. These times do not necessarily reflect the official ignition and extinction times, but rather the time during which the fire was burning at a reasonable rate.

Atmospheric temperatures, wind speeds and wind directions were measured with a weather station suspended from a small tethered blimp, deployed after the burns ${ }^{8}$. Only the lateral variation of the wind direction was recorded. The vertical variation was estimated from empirical correlations [11]. The variation of both the lateral and vertical components of the wind vector are input parameters to the model, expressed in terms of a standard deviation to the mean direction. The importance of these inputs will be discussed below.

The first burn lasted about 47 minutes, during which time the area of burning surface varied from practically zero to the full area of the boom plus spillover. In all, 9 "pulses" of several minutes in duration occurred. Due to the unsteady burning, the downwind instruments detected a number of "hits" due to the fact that the smoke generated when the fire was small was not lofted very high. Figure 9 summarizes the model simulation of Burn 1, showing the atmospheric temperature profile, the plume cross section, and the "footprint" of ground level particulate concentration. Superimposed on this plot are the actual RAM readings, averaged over the time of the burn. (A clearer display of the "footprints" for all three burns plus the average RAM readings are shown in Figure 12.) It is clear by looking at both the model predictions and the RAM data that ground level concentrations are by no means uniform either in space or in time, due in part to random fluctuations in wind direction, convective cells which are not explicitly accounted for in the model, small terrain effects, and unsteady burning of the fuel. Also, the real-time aerosol monitors used in the experiment recorded total PM-10 particulate. Most of this was indeed smoke, but some instruments registered short-term high readings at the time when a low-flying helicopter was in the vicinity. Nevertheless, the agreement between model and experiment is quite good, showing particulate concentrations ranging from 0 to $80 \mu \mathrm{g} / \mathrm{m}^{3}$ along the narrow path over which the plume is lofted. In addition to ground level instruments, a small aircraft was used to fly in the vicinity of the plume and record plume positions at various times, as well as to photograph the burn site and the plume. According to flight track data, the plume top rose to a height of about 550 to $600 \mathrm{~m}$, in

${ }^{7}$ The heat of combustion is based on laboratory experiments of a number of crude oils.

${ }^{8}$ The wind speed for the second burn was too high to use the blimp, and the temperature profile was taken from the helicopter, the wind speed and direction estimated from the flight log of the aircraft and ground weather stations. 
good agreement with model predictions.

The second burn was conducted for two reasons. First, it provided a control with which to compare the two emulsion burns. Second, it served as a good test case to compare to the numerical model since the smoke yield and heat release rate from a large pool fire of unweathered, unemulsified oil are relatively well known from previous laboratory and meso-scale experiments [2], [4]. Figure 10 summarizes the model simulation of Burn 2. Of particular interest in this burn was the presence of a thermal inversion at about $300 \mathrm{~m}$. This inversion layer restricted the plume to a maximum height of about $400 \mathrm{~m}$, and again this altitude was verified by the accompanying flight track recorder from the aircraft. The wind variability for this burn was less than that recorded for the first or the third burn, yielding a plume which retained its basic shape and structure for about $10 \mathrm{~km}$.

Even though the fuel for the third burn resembled that of the first, the burn was much steadier than the first. This probably was due to a slight modification in the application of the emulsion breaker or the difference in wind speed. In any event, weather conditions on the day of the third burn (September 11) were so foggy that the helicopter, which had been used on previous days to place instruments in the field, was grounded. The wind was from the north, blowing directly over a river bed, but shifting about $10^{\circ}$ per hour. Because of the difficult terrain and poor visibility, the instruments were deployed within a kilometer of the pit except for one which was deployed about 3 kilometers further downwind. Figure 11 summarizes the numerical simulation of the third burn. 

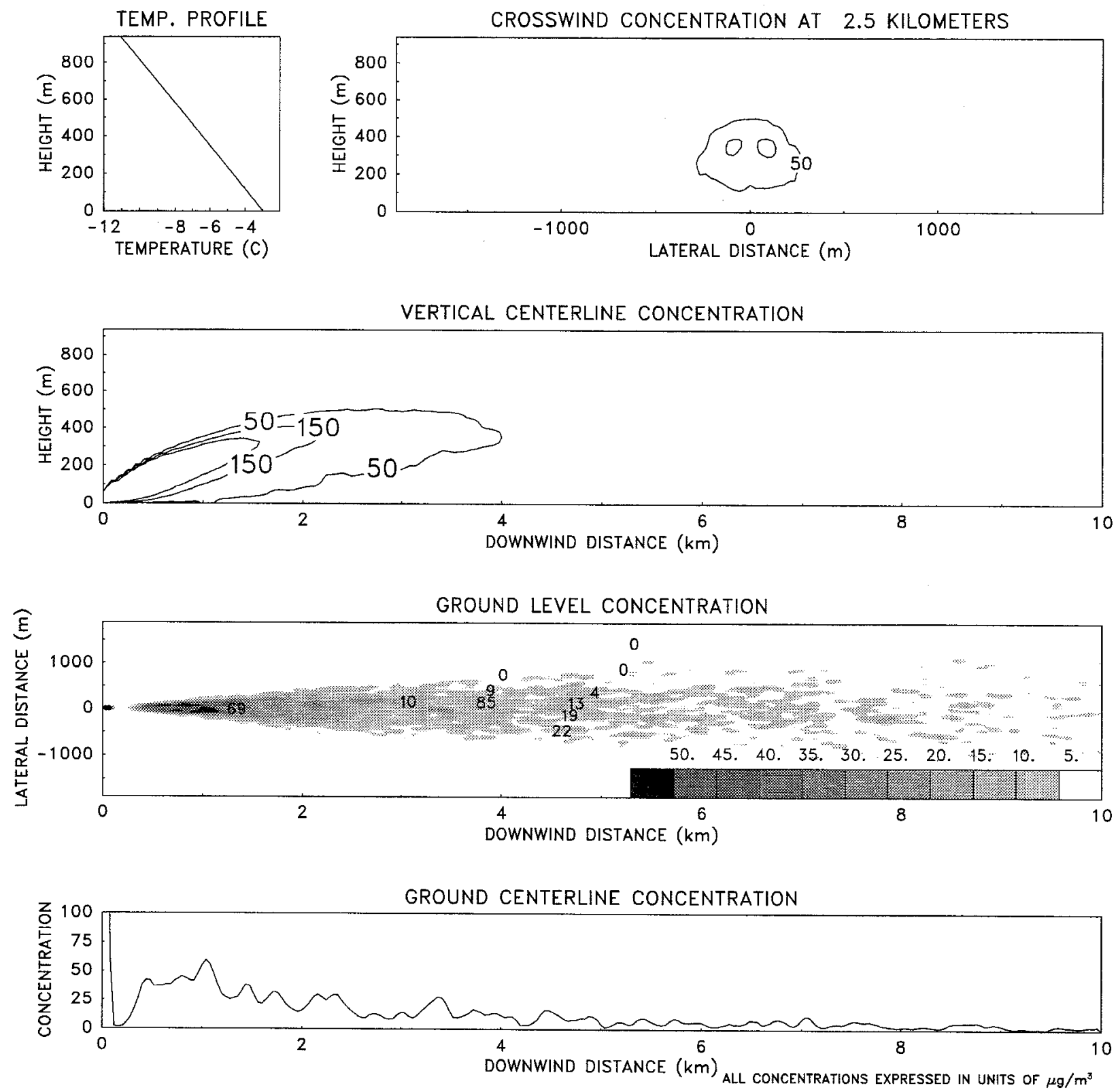

Figure 9: Summary of the numerical simulation of the first ACS Emulsion Burn. The parameters labeled "WIND STAND. DEV." are the lateral and vertical standard deviations of wind direction, respectively. Shown in the upper left is the temperature profile of the atmosphere obtained with a sounding blimp. To the right is a cross section of the plume. Below that is a centerline profile of the plume showing particulate concentrations in units of $\mu \mathrm{g} / \mathrm{m}^{3}$. Below that is a "footprint" of the ground level particulate concentration along with the recorded RAM averages shown at the locations where the instruments were deployed. A more detailed presentation of the footprint and RAM data is in Figure 12. The final plot aids in quantifying the footprint concentrations along the centerline. 
ACS BURN 2

WIND SPEED $9.0 \mathrm{~m} / \mathrm{s}$

HEAT LOADING 167. MW

WIND STAND. DEV. $8 .^{\circ}, 60^{\circ}$ MASS LOADING $.51 \mathrm{~kg} / \mathrm{s}$
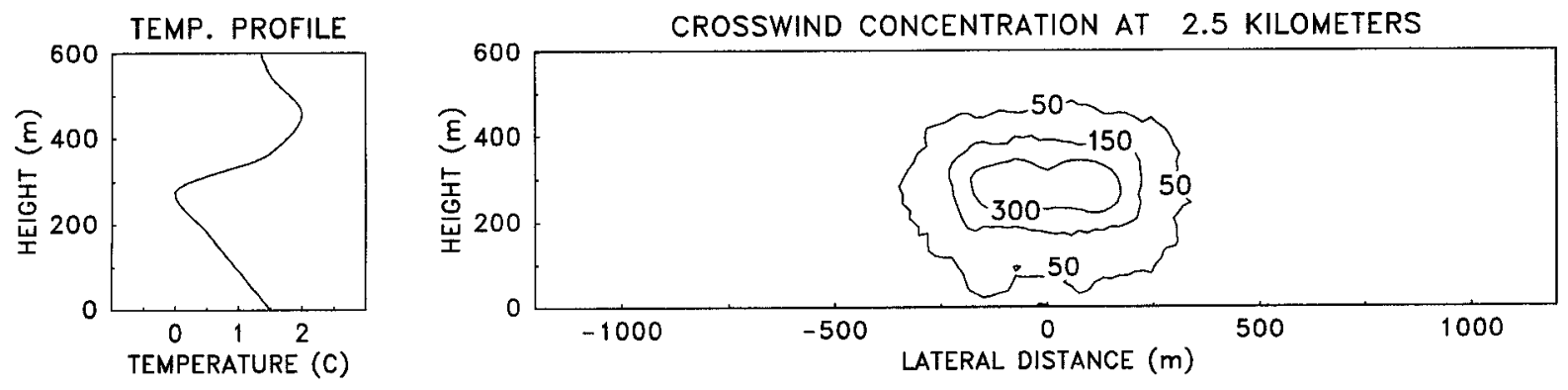

VERTICAL CENTERLINE CONCENTRATION
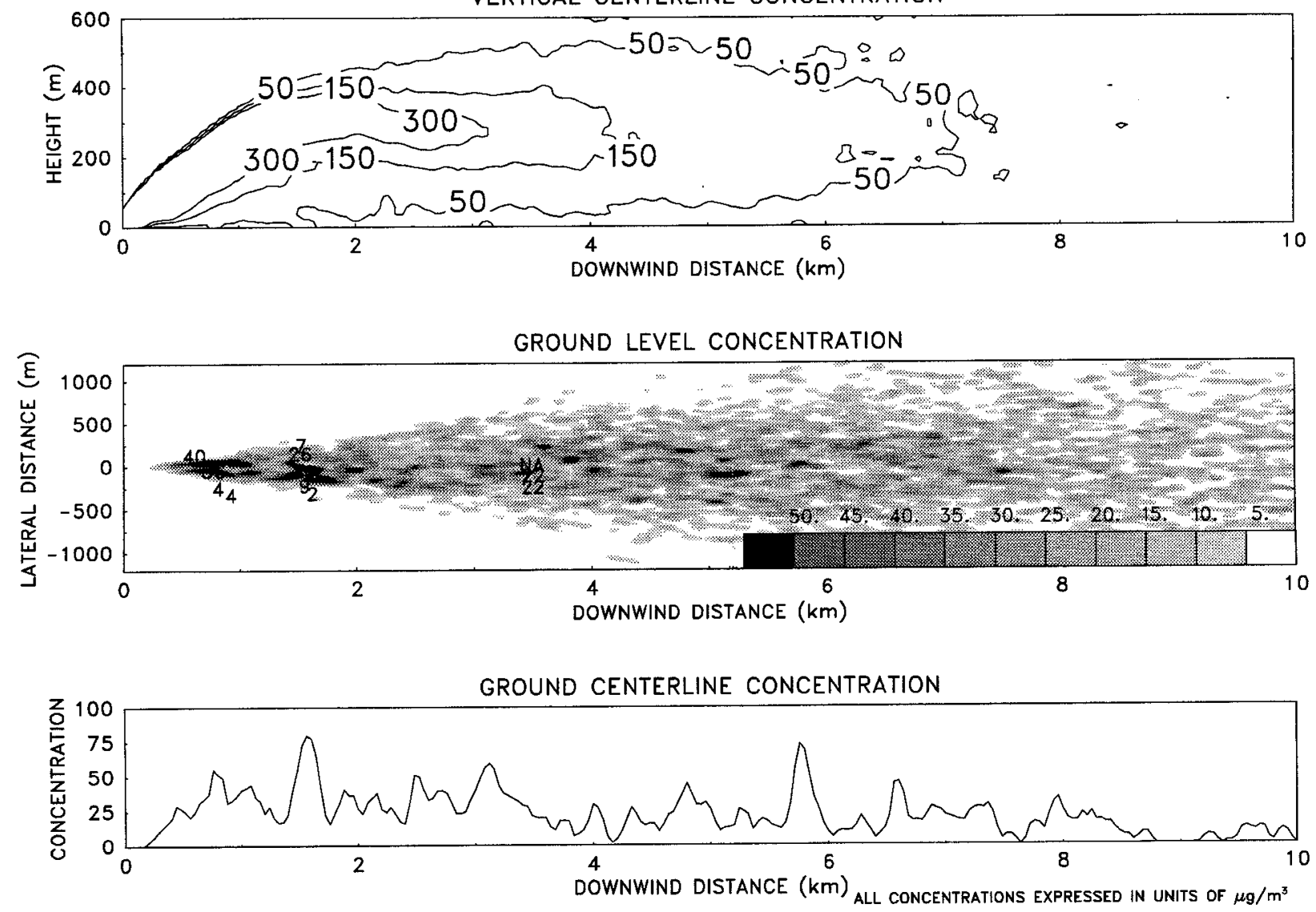

Figure 10: Summary of the numerical simulation of the second ACS Emulsion Burn. A more detailed presentation of the footprint and RAM data is in Figure 12. 
ACS BURN 3

WIND SPEED $4.5 \mathrm{~m} / \mathrm{s}$

HEAT LOADING 88. MW

WIND STAND. DEV. $15 .^{\circ}, 100^{\circ}$

MASS LOADING $0.27 \mathrm{~kg} / \mathrm{s}$
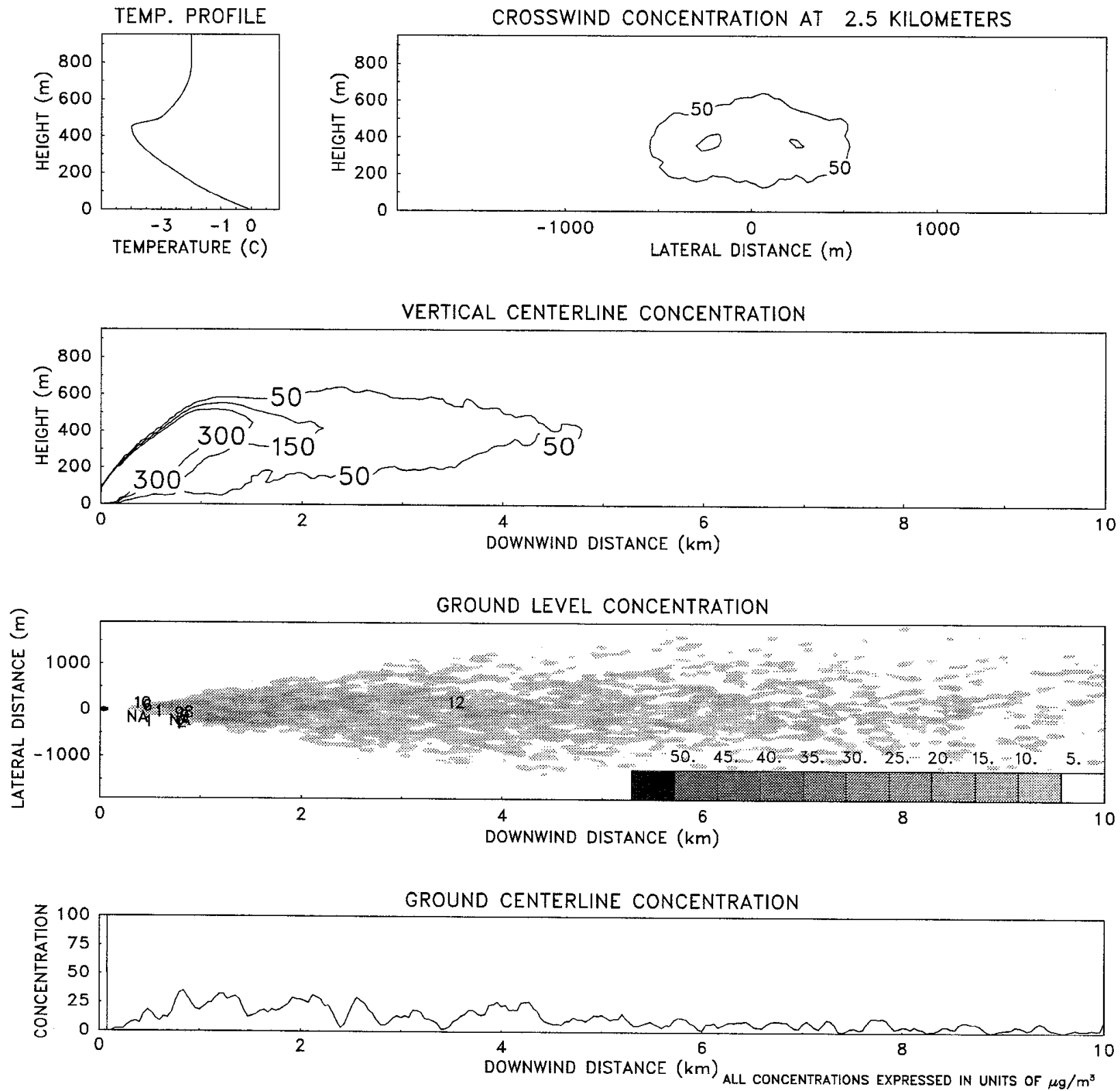

Figure 11: Summary of the numerical simulation of the third ACS Emulsion Burn. A more detailed presentation of the footprint and RAM data is in Figure 12. 

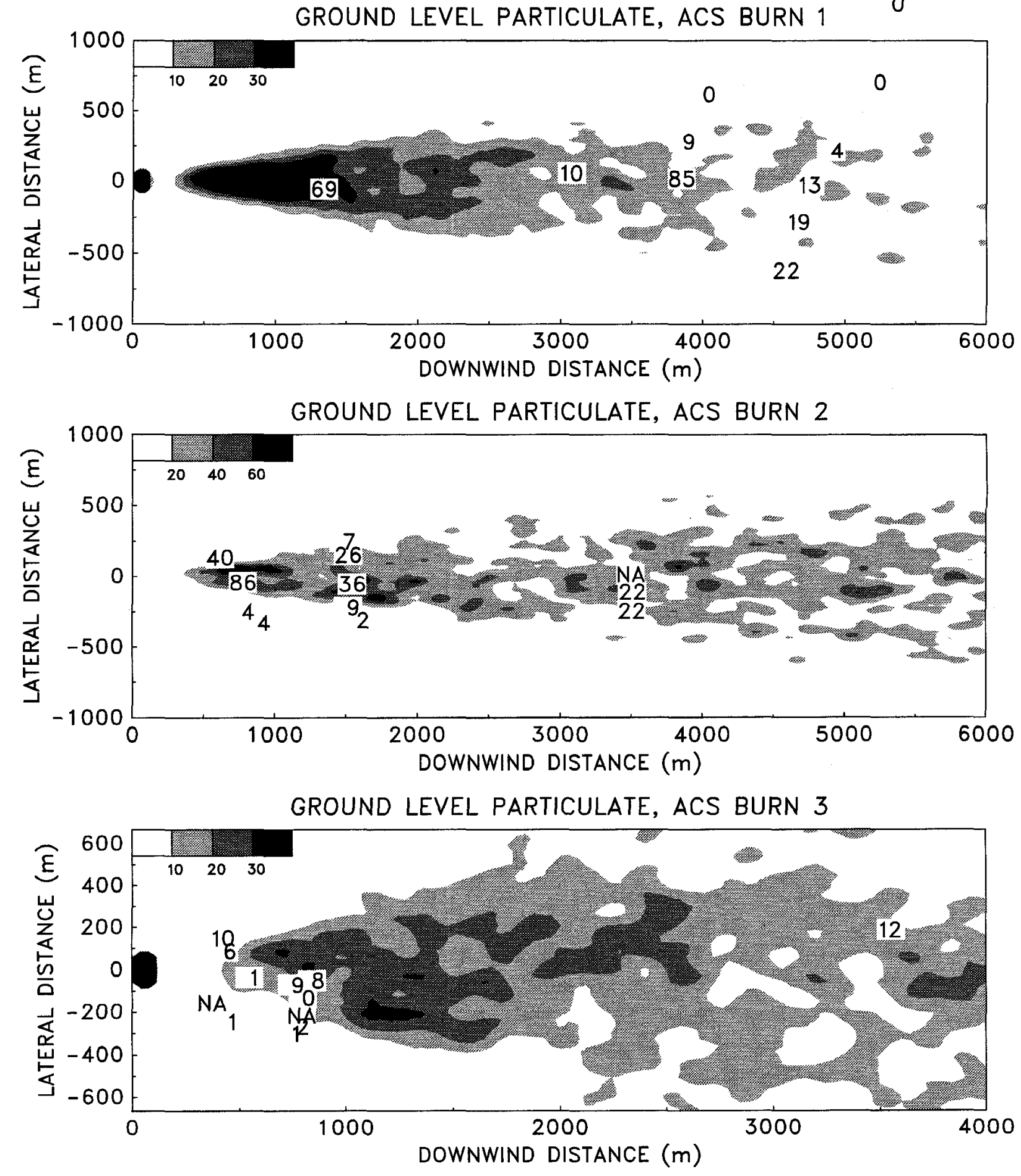

Figure 12: A summary of the ground level particulate concentration from the three ACS burns. Superimposed on the LES model predicted ground level particulate "footprint" are the actual averaged RAM readings at the locations where the instruments were deployed. 


\section{DISCUSSION}

The comparison of model predictions and experimental measurements is very favorable, and greatly increases the confidence in the methodology. This assessment is based simply on a visual survey of the available data. In order to make a more quantitative assessment of agreement, one must first consider the sources of uncertainty, which can basically be broken down into three major categories: 1 . Uncertainty in the model, 2. Uncertainty in the model inputs, and 3. Uncertainty in the experimental measurements. Each will be described in more detail.

1. Uncertainty in the model. Quantifying the uncertainty of the model is the purpose of most validation work, including this one, but it is often very difficult to distinguish model uncertainty from input uncertainty. Model uncertainty is due either to (a) the discretization in space and time of the partial differential equations which describe the introduction of hot gases into the atmosphere; or (b) the simplified physics used to derive these equations. The first is a small source of error, given the relatively good resolution of the computational grid over which the continuum equations are discretized. For most calculations performed to date, convective motion is resolved down to length scales on the order of 5 to 10 meters. This resolution adequately captures the large scale mixing of the hot gases from the fire with the surrounding atmosphere. The uncertainty due to the simplified physics is a greater concern. Physical assumptions and simplifications are necessary for a relatively fast, robust and efficient numerical model, but it is important not to eliminate vital physical features of the problem. Some features which can be important like terrain effects and thermal radiation have been left out of the current version of the model for simplicity, but may be incorporated later if the situation warrants it. To include in the model every conceivable meteorological phenomenon would be difficult, and most likely would yield only minor changes in the results obtained thus far. The same can be said about the details of the fire itself. For the scenarios under consideration in this report, the present physical description of the smoke plume is fairly accurate. Experience with this type of numerical simulation model for this and other problems has led to an overall assessment of the uncertainty ${ }^{9}$ of roughly $10 \%$.

2. Uncertainty in model inputs. Even if the physical model were perfect, the accuracy of its prediction would still depend on the accuracy of the input parameters. These parameters include the heat release rate and smoke yield of the fire itself, the wind speed, the wind variation, and the temperature profile of the atmosphere. For the experiments performed in this study, these parameters each carried an uncertainty of about $20 \%$. A large part of the uncertainty is due to the fact that these quantities can vary in space and time. For example, the heat release rate of the fire may vary over the course of a burn or the temperature profile three kilometers downwind may be different from what it is at the burn site. Uncertainty due to temporal variations in the input parameters are alleviated somewhat by the timeaveraging of results. For example, for the first and third Alaska Clean Seas burns,

${ }^{9}$ The term uncertainty in this report denotes a relative expanded uncertainty. That is, an uncertainty of $10 \%$ means that the true value of whatever is being measured is believed to be within $10 \%$ of the estimated value. 
where emulsions were used as fuel, there was considerable uncertainty in the burning rate because steady burning was not achieved and the burning characteristics of the emulsions were not well known. However, an estimate of the average burning rate as an input to the model yielded results in good agreement with time-averaged measurements taken in the field. However, for the Newfoundland burns, the data collected in the field was not time-averaged, but rather instantaneous. Thus, the experimental measurements reflect the temporal and spatial variation of the input parameters whereas the model results are by definition time-averaged. The LIDAR cross sectional images are instantaneous snapshots of the plume and are very sensitive to burning and meteorological conditions leading up to the time when the measurements are made. It would be nearly impossible to record and then input to the model these fine details so as to reproduce instantaneous characteristics of the smoke plume.

3. Uncertainty in experimental measurement. It has generally been assumed throughout this report that the experimental measurements represent the "truth". It should be pointed out, however, that the measurement techniques themselves are not perfect, and each has associated with it an uncertainty. Direct measurements like the real-time aerosol monitoring of smoke particulate have an uncertainty of about $10 \%$, whereas the quantification of LIDAR measurements has an uncertainty of about $50 \%$. Compounding the difficulty in interpreting the LIDAR data from NOBE is the fact that the plume was spread laterally by the wind shear, making it difficult to define perpendicular cross sections or a centerline.

Of the two sets of burn experiments, the Alaska Clean Seas burns were more useful for the present exercise. The NOBE burns were not designed for downwind monitoring, and the data collected by the University of Washington aircraft is the only data available. The plume itself was very complex due to the severe wind shear, and even though it presented a challenge for the numerical model, it was not an ideal case to test the accuracy of the model due to both uncertainty in the experimental measurements and the input parameters. Of the three ACS burns, the one most favorable for comparison purposes was the second Alaska Clean Seas burn. The fuel for this burn was unemulsified crude oil whose burning characteristics were measured in a laboratory, the winds were steady, and the fire burned relatively steadily for the duration of the burn. These conditions are consistent with the assumptions of the numerical model, thus it is not surprising that this burn yielded good results. However, to emphasize the effect of the input uncertainties described above, an identical calculation was performed, but with a one degree change in the standard deviation of the vertical component of the wind direction, which was estimated to be $6^{\circ}$. This one degree change is well within the uncertainty of this parameter, and it yielded roughly a $15 \%$ change in the ground level particulate concentration. Thus, the agreement between the experimental measurements and the model prediction shown in Figure 12 is well within the range of uncertainty associated with the input parameters, which in this case is about $20 \%$ for each. Similar sensitivity studies yielded similar results. The degree of accuracy of the prediction can not be quantified further.

Beyond comparing model and experimental results, the issue still remains of how representative are the experiments (and the hypothetical modeling studies) of an in situ burn of an accidental spill of crude oil. The Newfoundland experiment clearly has been 
the most realistic exercise to date, but those burns were conducted under reasonably good burn conditions, i.e. flat seas, modest winds and no precipitation. What would happen if the burns were conducted close to shore in heavier seas with winds blowing the smoke over land? In the absence of experiment, it is left to the numerical models to predict the results. What is difficult about this type of effort is that now one has to consider a much greater variety of meteorological and geographical conditions. It is virtually impossible to consider every possible scenario. Ultimately, the decision makers will have to use judgement and common sense when using numerical predictions because it is almost certain that an actual spill scenario will not correspond exactly to any particular hypothetical scenario.

An example of how one needs to employ good judgement to augment the limited set of model predictions would be in the case of a moving source. In each numerical simulation of a burn performed thus far, it has been assumed that the fire is fixed at one location. However, in an actual burn, the burning oil will be confined within a boom which will be towed through the water at a speed of about 1 knot so as to maintain a thick layer of oil. In addition, the fire and tow boats will all drift with the current. How will this effect the numerical results? Fortunately, there is no need to modify the numerical model, but rather reinterprete previously computed results. If it can be assumed that the fire moves slowly from some location $A$ to another location $B$ during the course of a burn, then the average ground level concentration at any point $C$ downwind may be estimated by working within a frame of reference whose origin is the fire. In this frame of reference, the fire is stationary, and the point of interest $C$ traverses a path opposite to the one taken by the fire. Thus for a given smoke plume "footprint" such as those in Figure 12, the concentration at a fixed location downwind of a moving fire can be obtained by averaging the concentration values along a path which represents that fixed position relative to the fire during the course of a burn. The end result of this exercise is that predicted time-averaged particulate levels downwind of a stationary burn will decrease overall due to the increased area over which the smoke is spread. It is not necessarily true that a moving source will always lead to a local decrease, because obviously if the fire is moving towards a fixed location, the particulate concentrations will increase above the level generated by a non-moving source.

\section{CONCLUSION}

In the present report, experimental data collected at two sets of mesoscale burns were compared with the results of the LES model run using the recorded meteorological and physical conditions. The results show that the predictions of the LES model are in good agreement with the experimental measurements given the uncertainty of the input parameters. These results increase confidence in the original study, and they provide guidance on how to assess the uncertainty of model predictions. The original report was written without the benefit of field data to validate the physical assumptions of the model; thus it was suggested that a factor of safety of 2 be applied to a model prediction to account for both the uncertainties in the input parameters and the physical assumptions of the model. The results of the field experiments, however, suggest that the uncertainty of the model prediction is commensurate with the uncertainty of the input parameters. This 
is not to say that the model is perfect, but rather that the uncertainty due to the physical assumptions of the model are outweighed by the uncertainty due to the input parameters.

The original study [2] considered single fires of up to 2 gigawatts in size contained within the confines of a boom, and smoke plumes lofting over relatively flat terrain. If a planned in situ burn falls within the range of parameters considered in that study, then the level of confidence of the prediction is commensurate with the level of confidence of the input parameters. If the scenario of concern falls outside of the parameter range considered, then the results of the study must be used with appropriate caution.

\section{ACKNOWLEDGEMENTS}

This work was sponsored by the Alaska Department of Environmental Conservation (ADEC). The LES model and experimental techniques for smoke measurement used in this work were developed in part under funding provided by the Minerals Management Service, US Department of the Interior. Additional thanks to Ronald Ferek and John Ross of the University of Washington for their data and assistance from the Newfoundland experiment, Nick Glover and Bruce McKenzie of Alaska Clean Seas for allowing NIST to participate in their Burning of Emulsions project, Phil Campagna and the Emergency Response Team of the US Environmental Protection Agency for gathering particulate data under adverse conditions at Prudhoe Bay, Nir Barnea and John Whitney of NOAA and Joseph Mullin of MMS who assisted in the data collection at Prudhoe Bay. 


\section{REFERENCES}

[1] Whitney, J., Lautenberger, C. and Dietrick, L., "Alaska Regional Response Team In Situ Burn Guidelines and Pre-Approvals," Proceedings of the 17th Arctic and Marine Oil Spill Program (AMOP) Technical Seminar, Vancouver, BC, June 8-10, 1994, pp. 419-437.

[2] McGrattan, K.B., Putorti, A.D., Twilley, W.H., and Evans, D.D., "Smoke Plume Trajectory of In Situ Burning of Crude Oil in Alaska", NISTIR 5273, National Institute of Standards and Technology, Gaithersburg, Maryland, 20899, October 1993.

[3] Baum, H.R., McGrattan, K.B. and Rehm, R.G., "Simulation of Smoke Plumes from Large Pool Fires", Proceedings of the 25th International Symposium on Combustion, University of California, Irvine, July 31-August 5, 1994, The Combustion Institute, Pittsburgh, pp. 1463-1469, 1994.

[4] Walton, W.D. et al., "In-Situ Burning of Oil Spills: Meso-scale Experiments and Analysis", Proceedings of the Sixteenth Arctic and Marine Oil Spill Program Technical Seminar, June 7-9, 1993, Calgary, Alberta, pp. 679-734.

[5] Fingas, M.F. et al., "The Newfoundland Offshore Burn Experiment-NOBE", Proceedings of the 1995 International Oil Spill Conference, Long Beach, California, Feb. 27 - March 2, 1995. American Petroleum Institute Pub. No. 4620, pp. 123-132.

[6] Walton, W.D., Twilley, W.H., McElroy, J., Evans, D.D., and Tennyson, E.J., "Smoke Measurements Using a Tethered Miniblimp at the Newfoundland Offshore Oil Burn Experiment", Proceedings of the Seventeenth Arctic and Marine Oil Spill Program Technical Seminar, June 8-10, 1994, Vancouver, British Columbia, pp. 1083-1098.

[7] Koseki, H. and Yumoto, T., "Air Entrainment and Thermal Radiation from Heptane Pool Fires", Fire Technology, February, 1988.

[8] Ferek, R., Ross, J.L. and Hobbes, P.V., "Airborne Sampling of Smoke Emissions from the Controlled Burn off Newfoundland", Final Report of the University of Washington to Environment Canada, March 1995, Contract No. KA168-3-1069-01-SS.

[9] McGrattan et al., "Smoke Plume Trajectory of In Situ Burning of Crude Oil in Alaska - Field Experiments", Proceedings of the Eighteenth Arctic and Marine Oil Spill Program Technical Seminar, June 14-16, 1995, Edmonton, Alberta, pp. 901-914.

[10] Buist, lan, "Demulsifiers and Modified Heli-Torch Fuels to Enhance In Situ Burning of Emulsions", Summary Report, S.L. Ross Environmental Research Ltd., Ottawa, Ontario, for Alaska Clean Seas, Anchorage, Alaska, February 1995.

[11] Slade, D.H. (ed.) Meteorology and Atomic Energy, 1968, Air Resources Laboratory, Environmental Science Services Administration, United States Department of Commerce, July, 1968. (Available through National Technical Information Service (NTIS), Department of Commerce, TID-24190) 


\section{APPENDIX: ACS EMULSION BURN RAM DATA}

On the following pages are the data from the RAMs (real-time aerosol monitors) used during the ACS Emulsion Burn to record ground level particulate concentrations. Shown in Figure 13 are the locations of the instruments for the three burns in relation to the burn pan. Following this are the readings of the RAMS for the three burns. There were 12 RAMs deployed for each burn. For Burn 2, RAM 10 malfunctioned. For Burn 3, RAMs 4 and 9 malfunctioned. The time shown on the RAM concentration plots report the time in minutes from ignition. Depending on the distance from the burn pit, it takes anywhere from 5 to 20 minutes following ignition for the smoke to drift overhead and be detected. The average of the readings taken well before the arrival of the smoke is subtracted from all of the readings; thus, the data presented is a measure of the particulate concentration above background. 


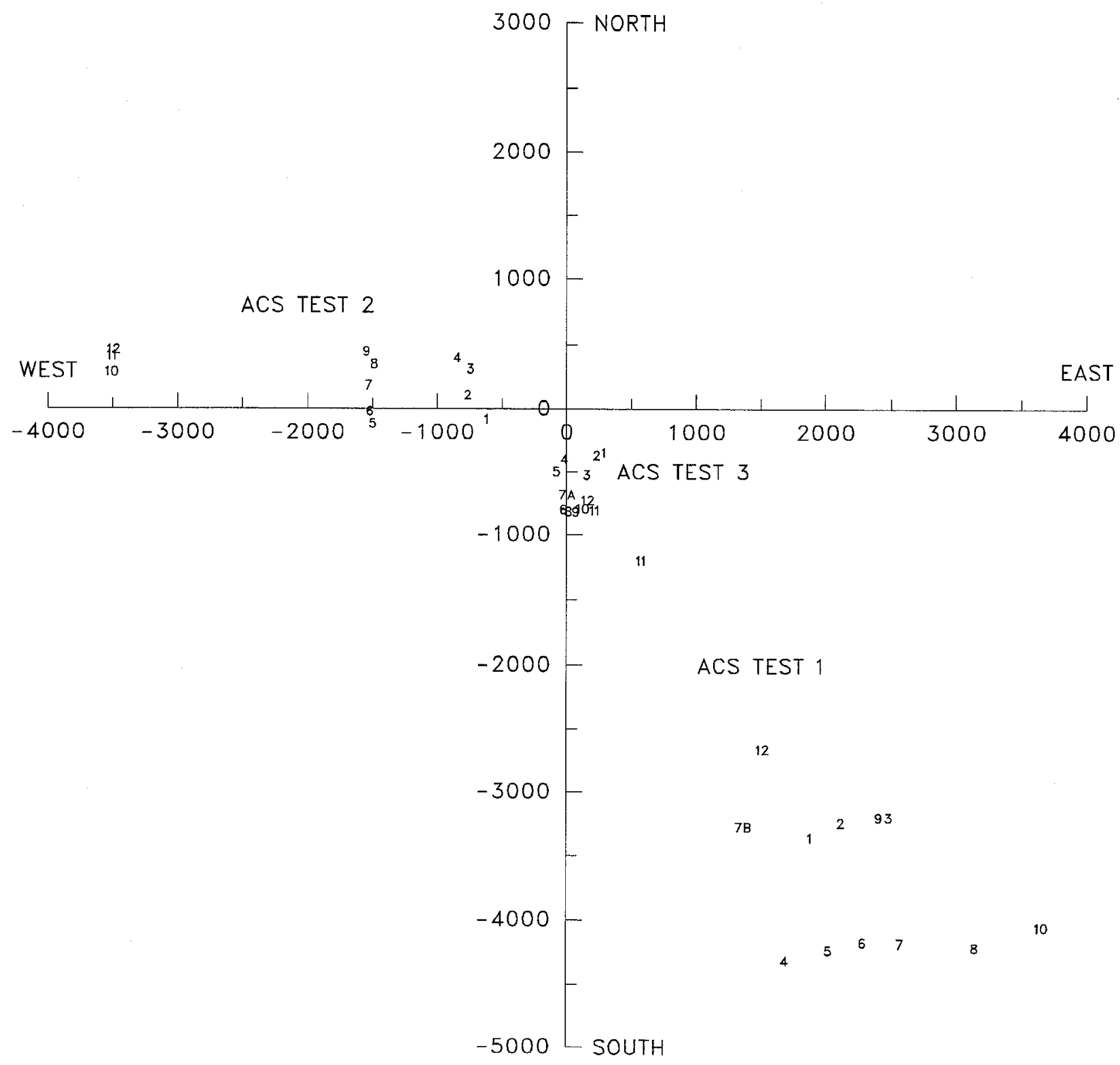

Figure 13: Location of the RAMs for the three ACS Emulsion Burns. All distances are in meters, and the origin represents the burn pit. The RAMs labeled 7A and 7B are from Test 3 and signify that the RAM was moved from the A position to the $B$ position halfway through the burn. 

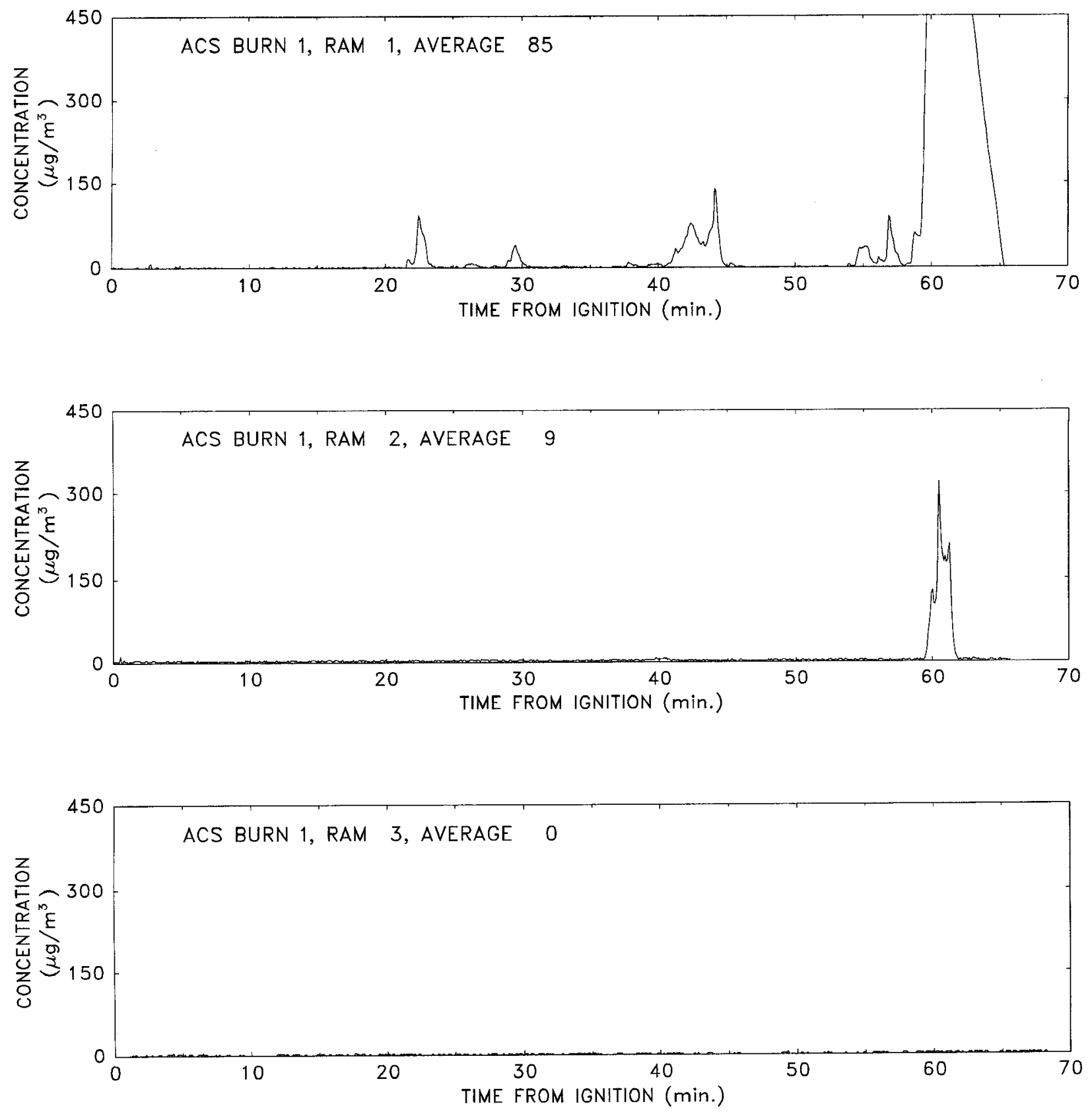

Figure 14: RAM data from Alaska Clean Seas Burning of Emulsions Test. Courtesy US Environmental Protection Agency, Emergency Response Team. 

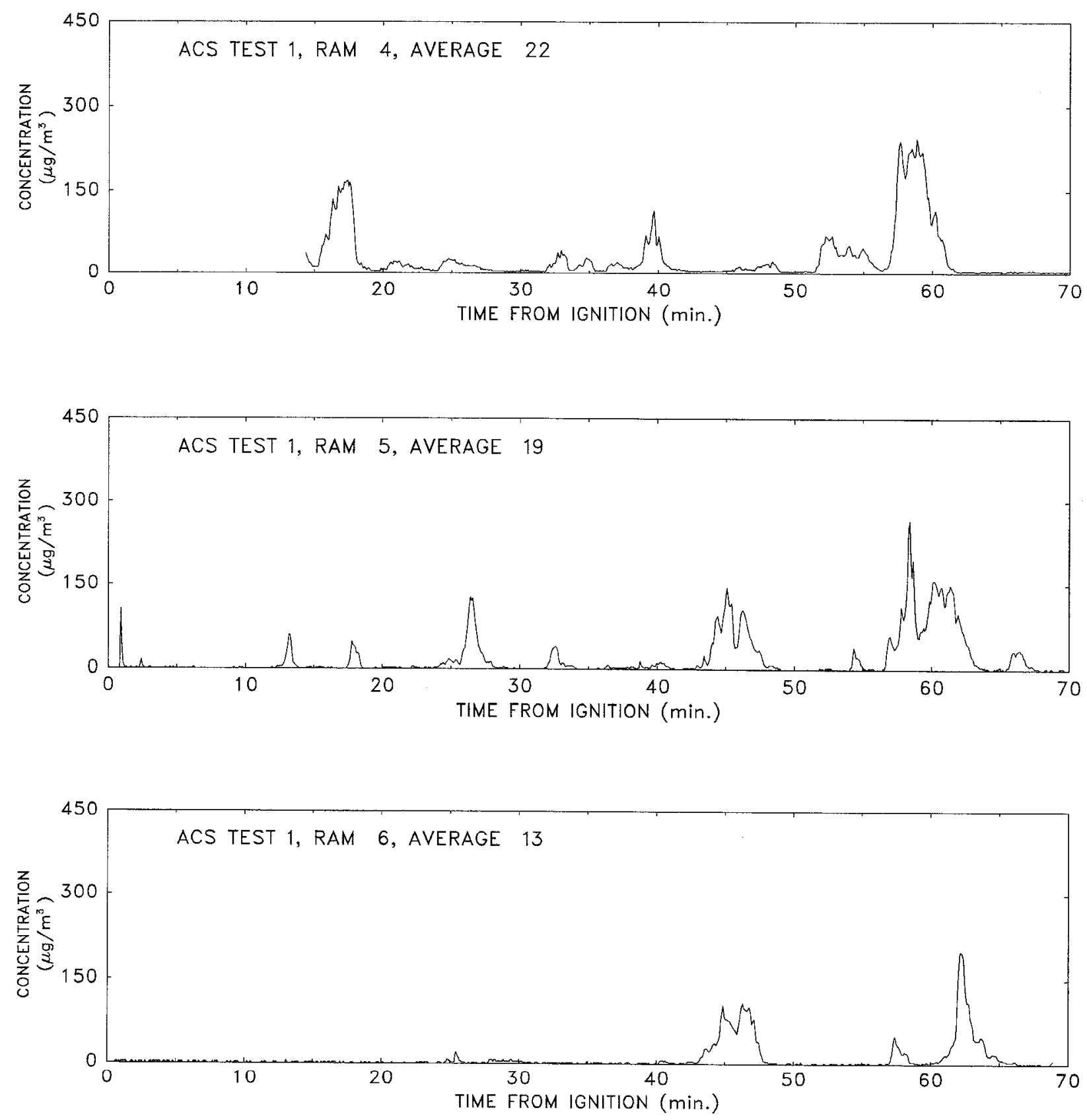

Figure 15: RAM data from Alaska Clean Seas Burning of Emulsions Test. Courtesy US Environmental Protection Agency, Emergency Response Team. 

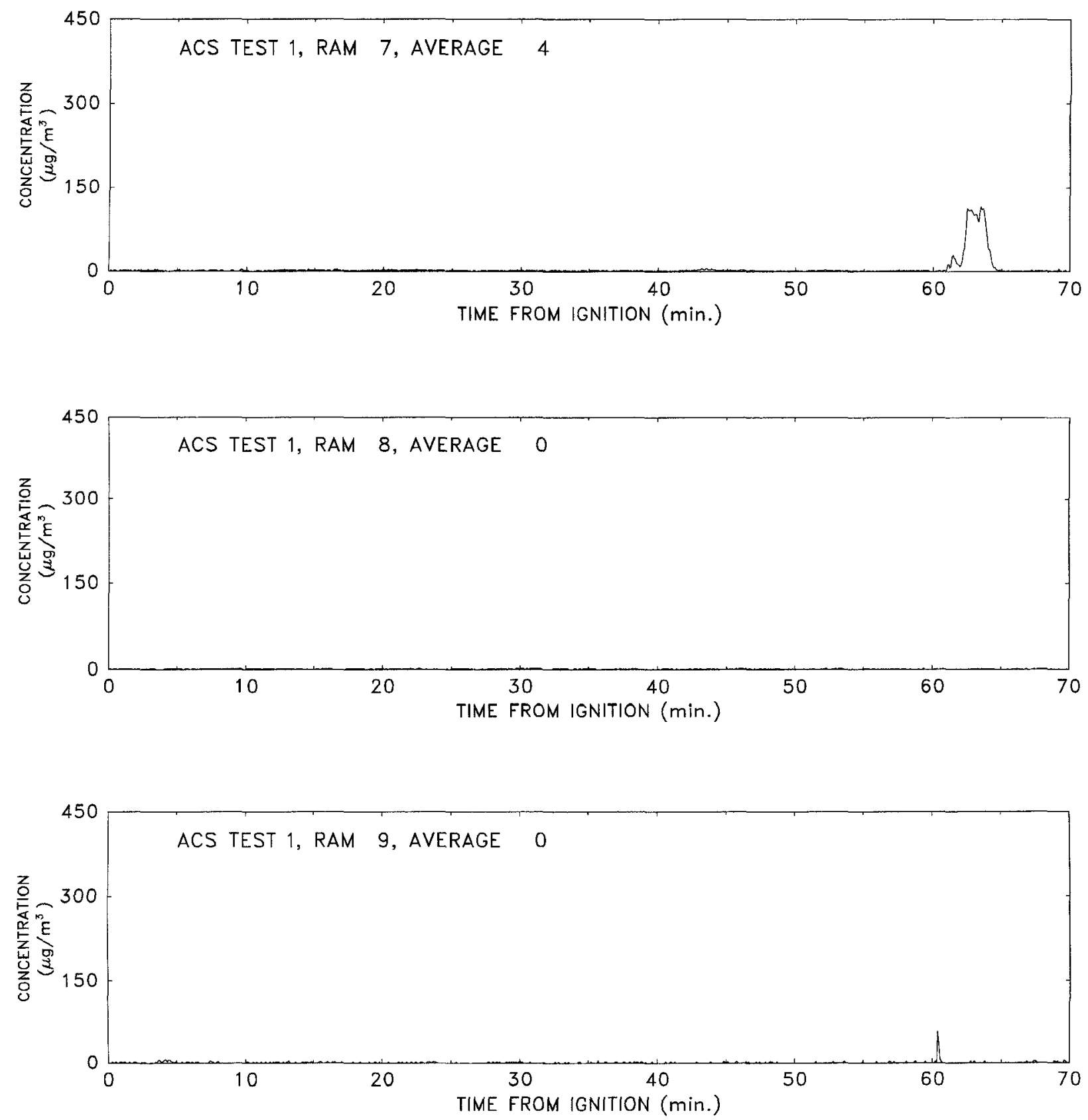

Figure 16: RAM data from Alaska Clean Seas Burning of Emulsions Test. Courtesy US Environmental Protection Agency, Emergency Response Team. 

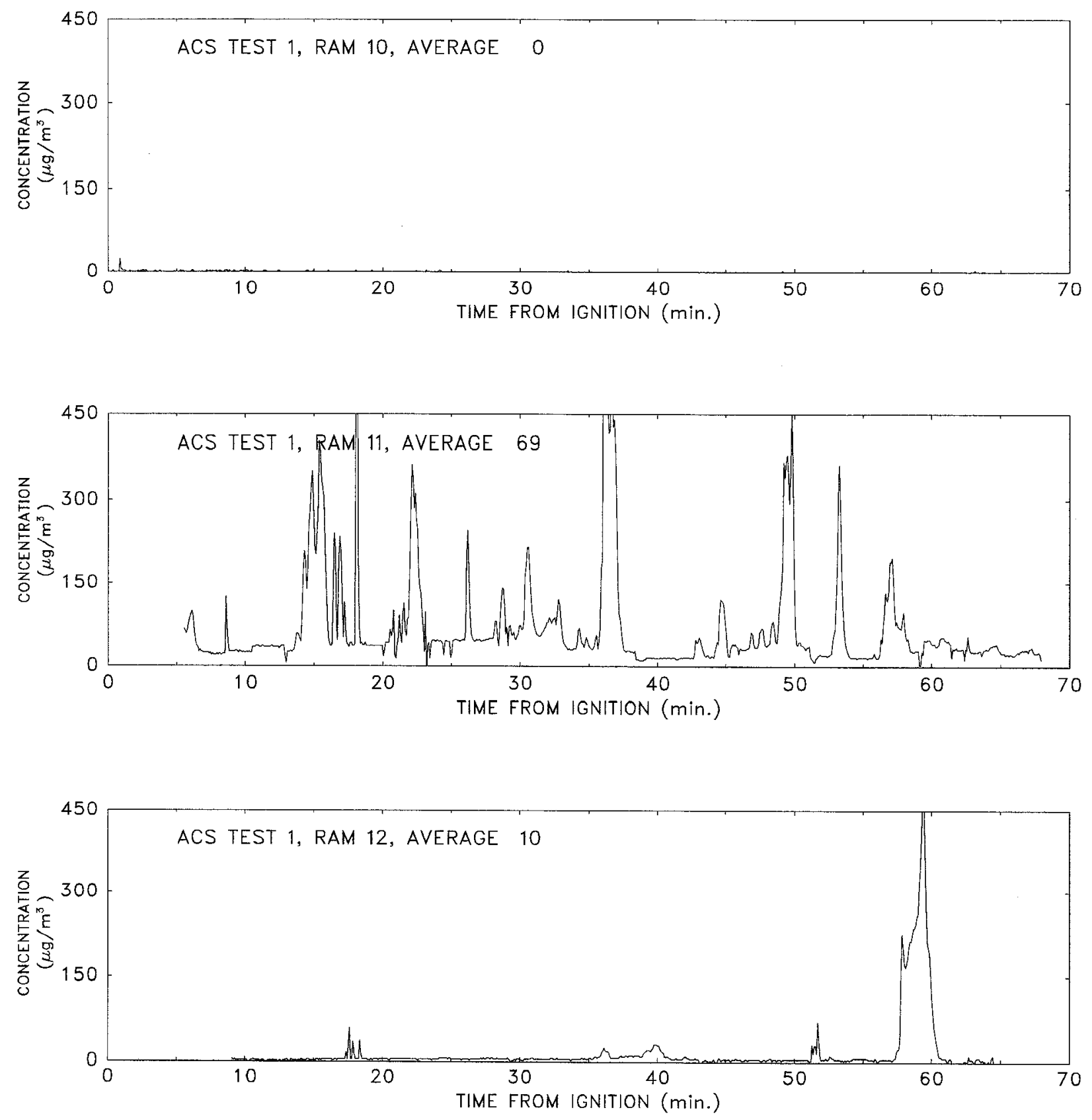

Figure 17: RAM data from Alaska Clean Seas Burning of Emulsions Test. Courtesy US Environmental Protection Agency, Emergency Response Team. 

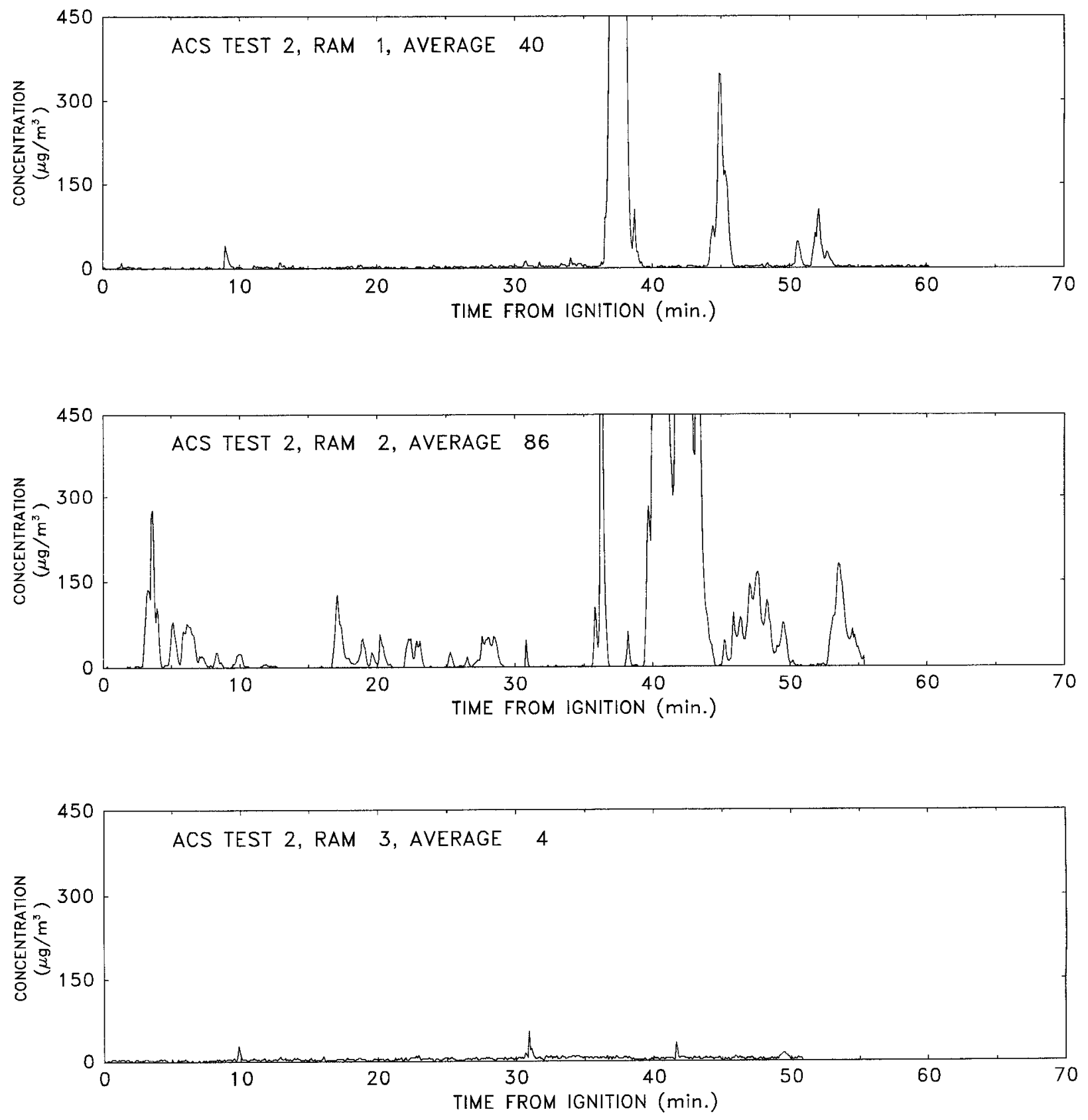

Figure 18: RAM data from Alaska Clean Seas Burning of Emulsions Test. Courtesy US Environmental Protection Agency, Emergency Response Team. 

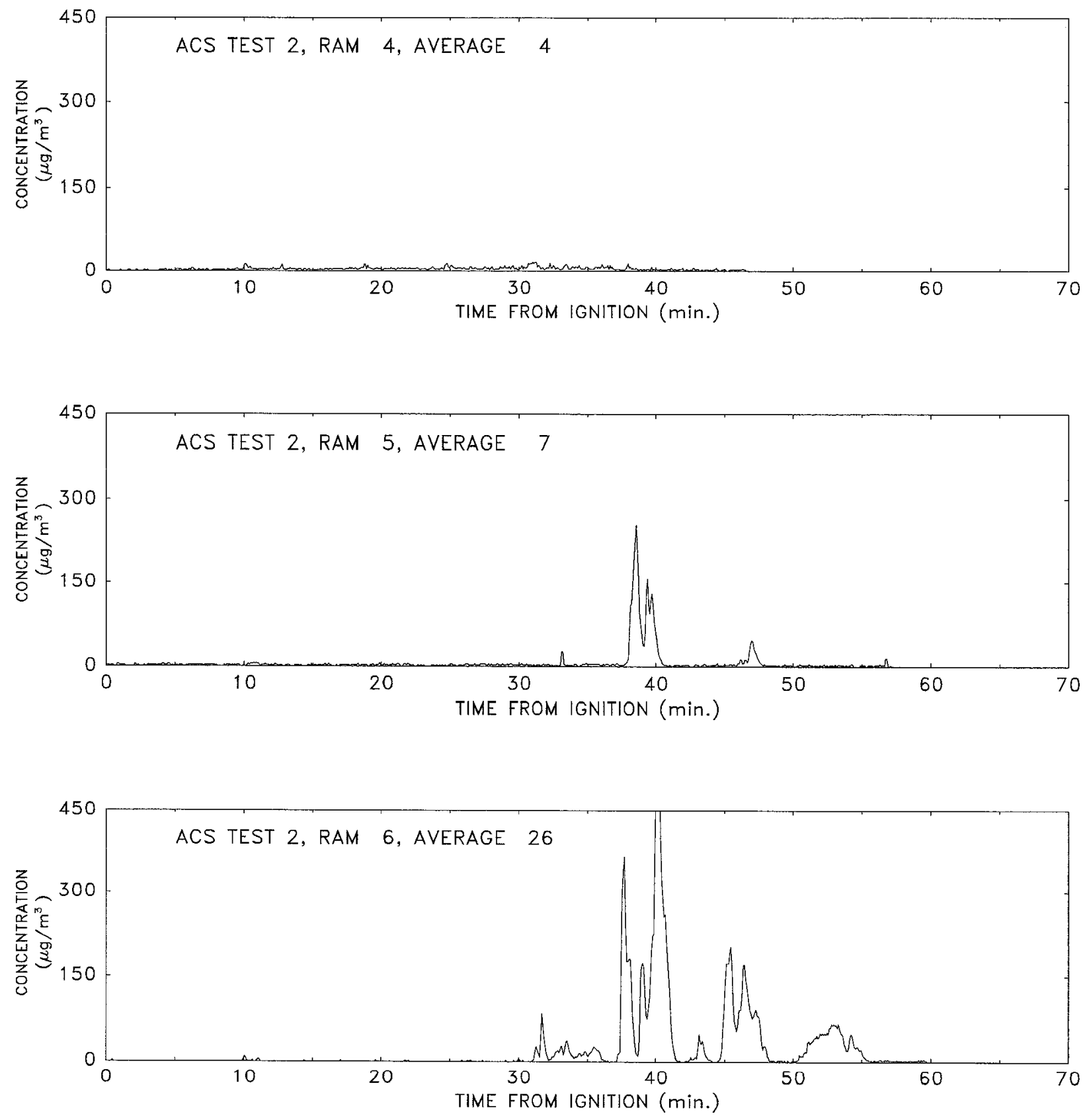

Figure 19: RAM data from Alaska Clean Seas Burning of Emulsions Test. Courtesy US Environmental Protection Agency, Emergency Response Team. 

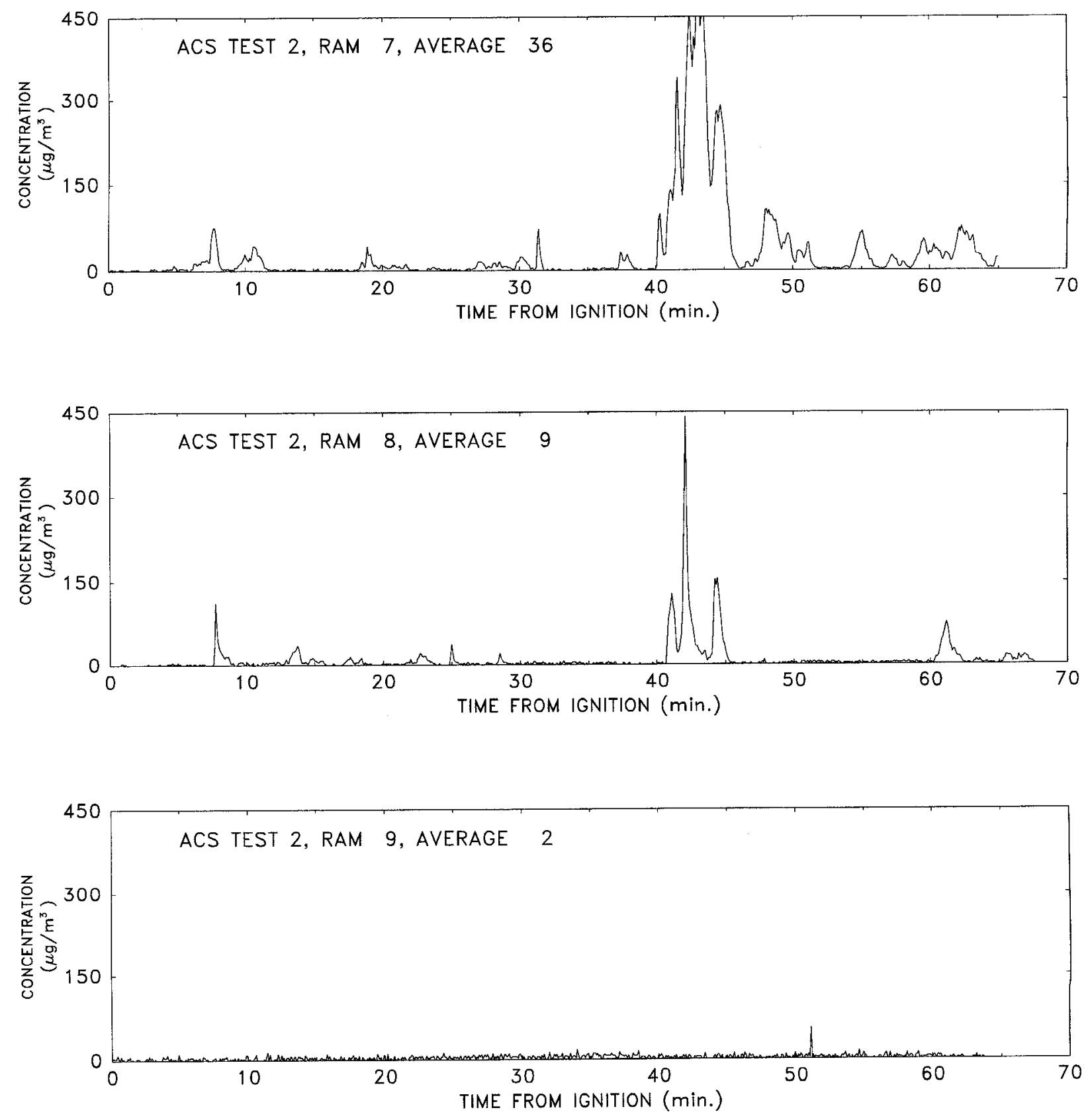

Figure 20: RAM data from Alaska Clean Seas Burning of Emulsions Test. Courtesy US Environmental Protection Agency, Emergency Response Team. 

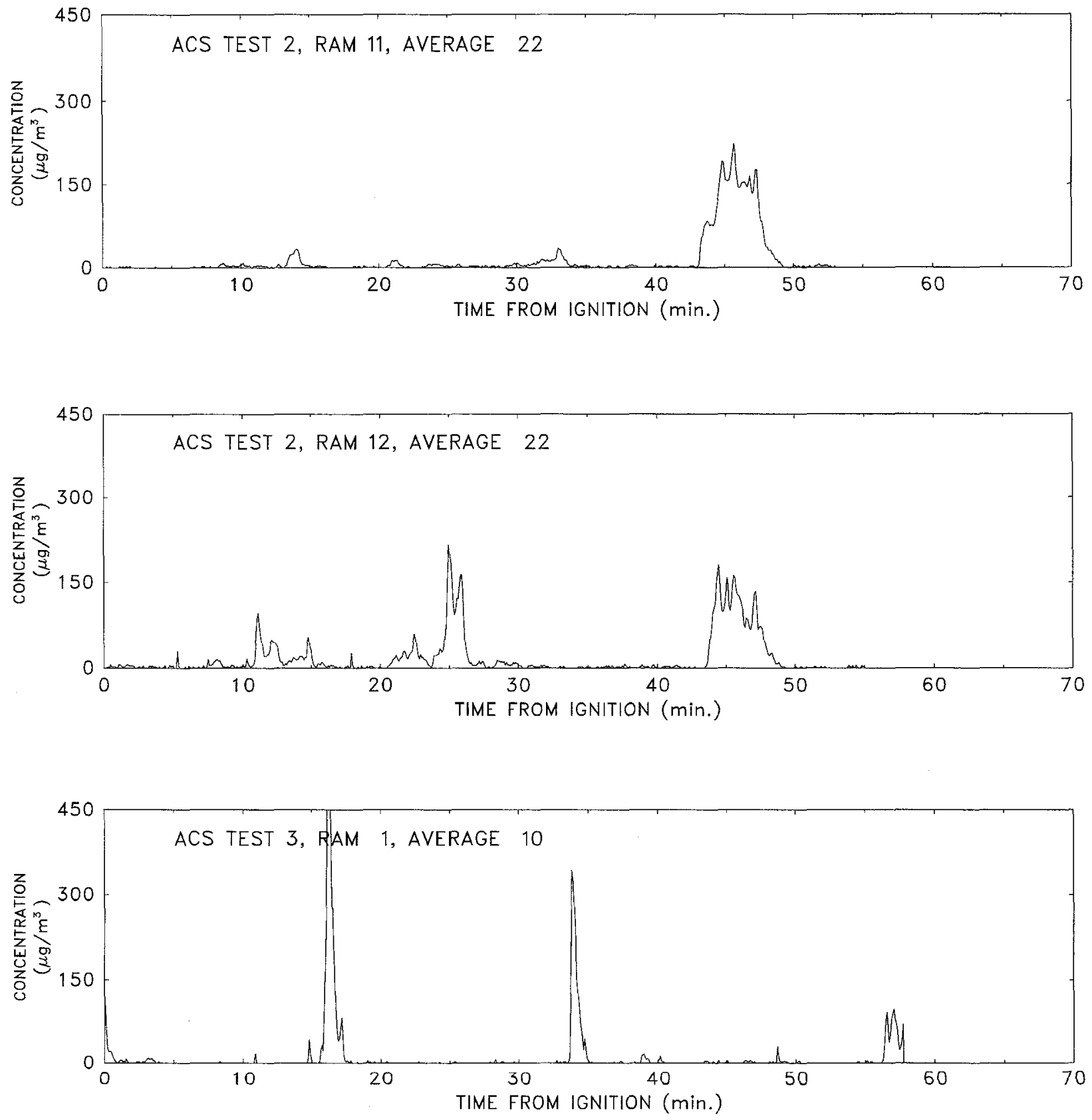

Figure 21: RAM data from Alaska Clean Seas Burning of Emulsions Test. Courtesy US Environmental Protection Agency, Emergency Response Team. 

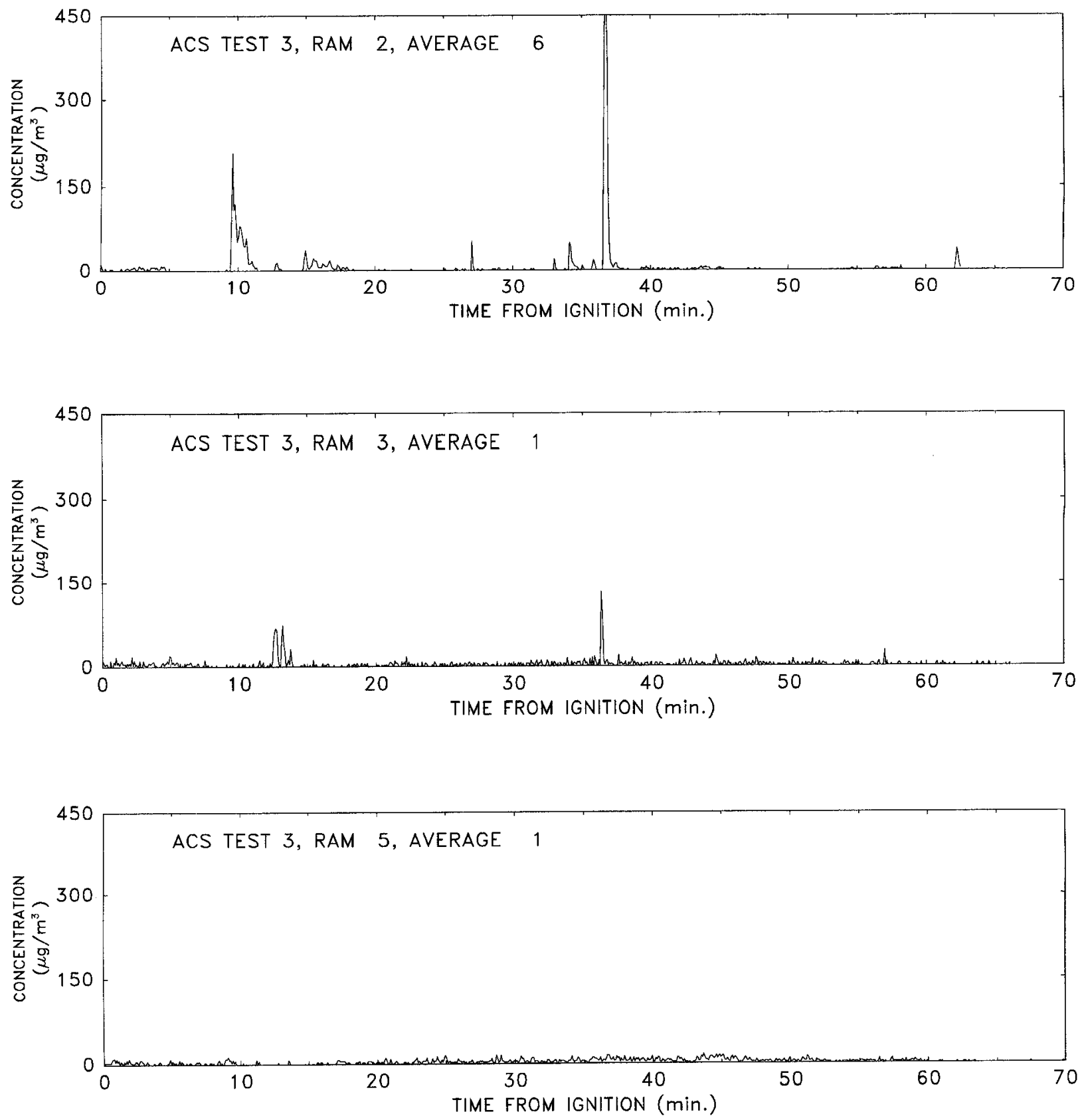

Figure 22: RAM data from Alaska Clean Seas Burning of Emulsions Test. Courtesy US Environmental Protection Agency, Emergency Response Team. 

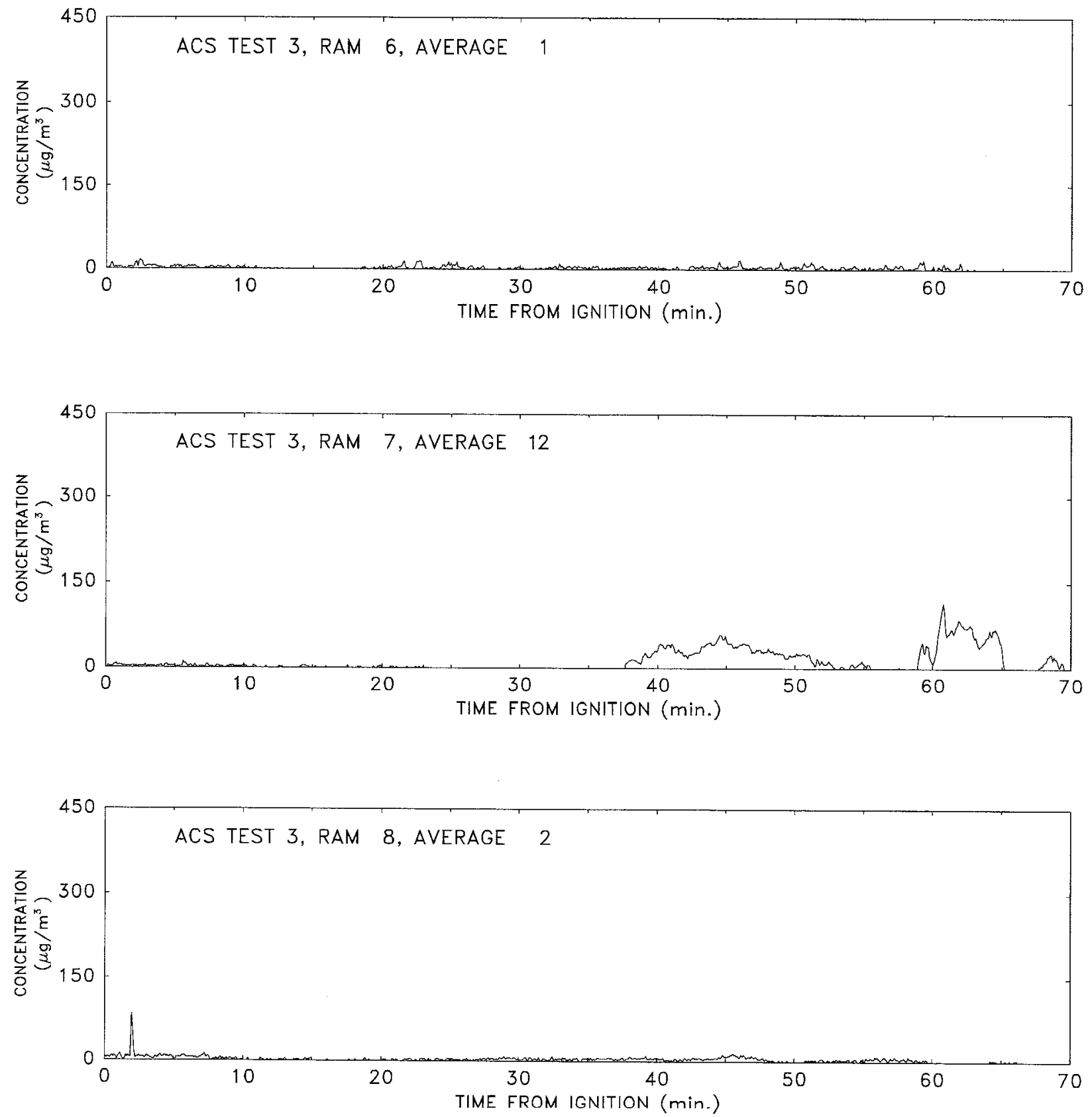

Figure 23: RAM data from Alaska Clean Seas Burning of Emulsions Test. Courtesy US Environmental Protection Agency, Emergency Response Team. Note that RAM 7 in Test 3 was moved after about 24 minutes, and started recording again at about 37 minutes. See the map for initial and final locations. 

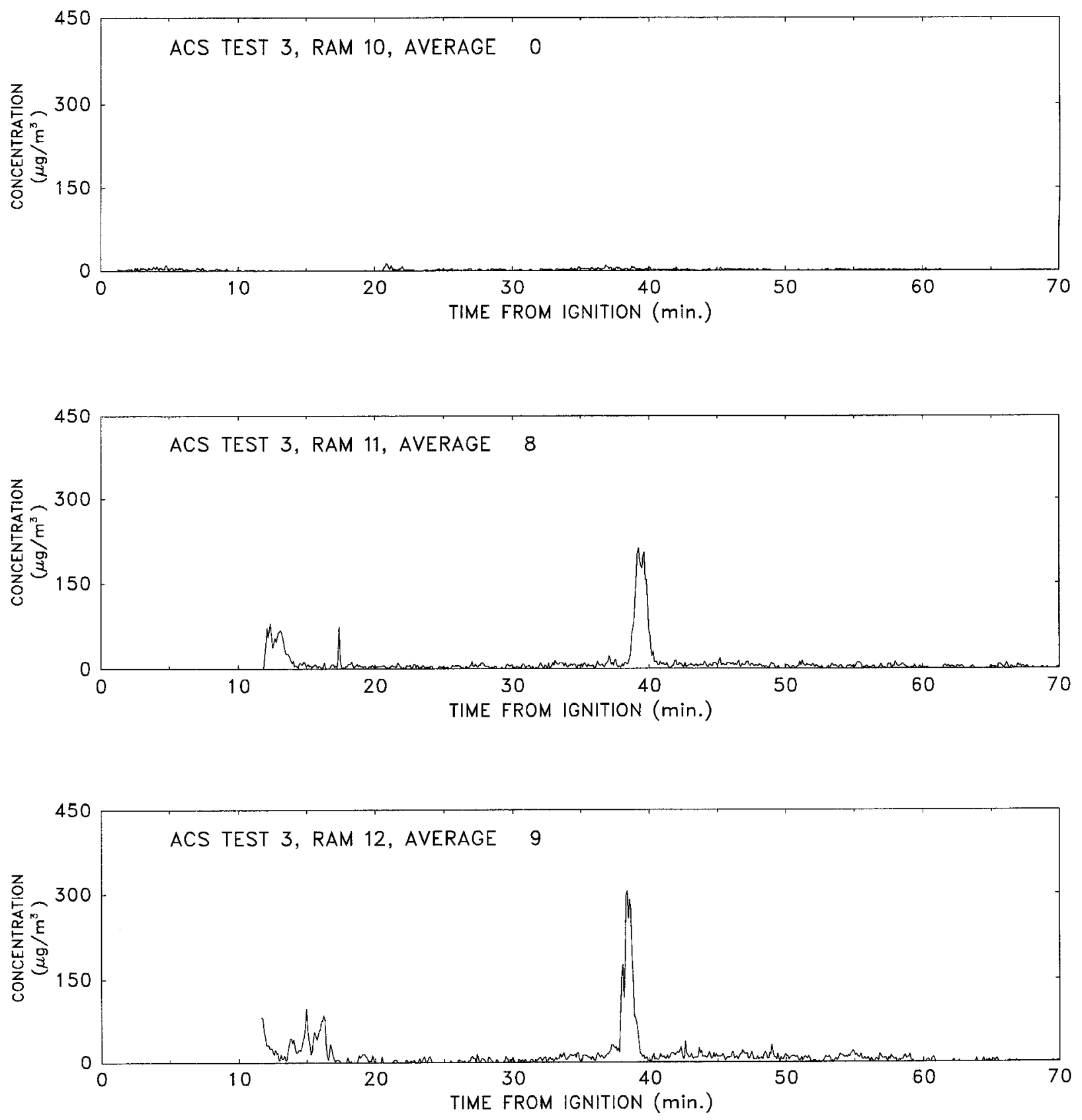

Figure 24: RAM data from Alaska Clean Seas Burning of Emulsions Test. Courtesy US Environmental Protection Agency, Emergency Response Team. 